\title{
AGOA Rules: The Intended and Unintended Consequences of Special Fabric Provisions
}

\section{Citation}

dwards, Lawrence, and Robert Z. Lawrence. 2011. AGOA Rules: The Intended and Unintended Consequences of Special Fabric Provisions. HKS Faculty Research Working Paper Series RWP11-002, John F. Kennedy School of Government, Harvard University

\section{Published Version}

http://web.hks.harvard.edu/publications/workingpapers/citation.aspx?Publd=7552

\section{Permanent link}

http://nrs.harvard.edu/urn-3:HUL.InstRepos:4669675

\section{Terms of Use}

This article was downloaded from Harvard University's DASH repository, and is made available under the terms and conditions applicable to Other Posted Material, as set forth at http:// nrs.harvard.edu/urn-3:HUL.InstRepos:dash.current.terms-of-use\#LAA

\section{Share Your Story}

The Harvard community has made this article openly available.

Please share how this access benefits you. Submit a story.

Accessibility 


\section{AGOA Rules: The I ntended and Unintended Consequences of Special Fabric Provisions Faculty Research Working Paper Series}

\section{Lawrence Edwards}

University of Cape Town

\section{Robert Z. Lawrence}

Harvard Kennedy School

\section{January 2011 RWP11-002}

The views expressed in the HKS Faculty Research Working Paper Series are those of the author(s) and do not necessarily reflect those of the John F. Kennedy School of Government or of Harvard University. Faculty Research Working Papers have not undergone formal review and approval. Such papers are included in this series to elicit feedback and to encourage debate on important public policy challenges. Copyright belongs to the author(s). Papers may be downloaded for personal use only. 
NBER WORKING PAPER SERIES

AGOA RULES: THE INTENDED AND UNINTENDED CONSEQUENCES OF SPECIAL FABRIC PROVISIONS

\author{
Lawrence Edwards \\ Robert Z. Lawrence \\ Working Paper 16623 \\ http://www.nber.org/papers/w16623
NATIONAL BUREAU OF ECONOMIC RESEARCH
1050 Massachusetts Avenue
Cambridge, MA 02138 \\ December 2010
}

We are grateful to Mark Bennett for his invaluable assistance on our visit to Lesotho; to the various people we interviewed including Nkopane Monyane, Jennifer Chen, Grace Lin, Mpho Madia, Fiona Lee and those from the Lesotho National Development Corporation; to Mike Morris for helpful conversations, to Pandey Bibek and Jenny O Connell for research assistance; and for funding to the NBER Africa project. We also thank the South African National Research Foundation, Economic Research Southern Africa and the Center for International Development at Harvard for hosting our visits to work together on this project. The views expressed herein are those of the authors and do not necessarily reflect the views of the National Bureau of Economic Research.

(C) 2010 by Lawrence Edwards and Robert Z. Lawrence. All rights reserved. Short sections of text, not to exceed two paragraphs, may be quoted without explicit permission provided that full credit, including $\odot$ notice, is given to the source. 
AGOA Rules: The Intended and Unintended Consequences of Special Fabric Provisions

Lawrence Edwards and Robert Z. Lawrence

NBER Working Paper No. 16623

December 2010

JEL No. F0,F14,O0,O24

\begin{abstract}
$\underline{\text { ABSTRACT }}$
Lesotho and other least developed African countries responded impressively to the preferences they were granted under the African Growth and Opportunities Act with a rapid increase in their clothing exports to the US. But this performance has not been accompanied by some of the more dynamic growth benefits that might have been hoped for. In this study we develop the theory and present empirical evidence to demonstrate that these outcomes are the predictable consequences of the manner in which the specific preferences might be expected to work.
\end{abstract}

The MFA (Multi-fiber Arrangement) quotas on US imports of textiles created a favorable environment for low value-added, fabric-intensive clothing production in countries with unused quotas by inducing constrained countries to move into higher quality products. By allowing the least developed African countries to use third country fabrics in their clothing exports to the US, AGOA provided additional implicit effective subsidies to clothing that were multiples of the US tariffs on clothing imports. Taken together, these policies help account for the program's success and demonstrate the importance of other rules of origin in preventing poor countries from taking advantage of other preference programs. प

But the disappointments can also be attributed to the preferences because they discouraged additional value-addition in assembly and stimulated the use of expensive fabrics that were unlikely to be produced locally. When the MFA was removed, constrained countries such as China moved strongly into precisely the markets in which AGOA countries had specialized. Although AGOA helped the least developed countries withstand this shock, they were nonetheless adversely affected. Preference erosion due to MFN reductions in US clothing tariffs could similarly have particularly severe adverse effects on these countries.

Lawrence Edwards

School of Economics

University of Cape Town

Cape Town

Republic of South Africa

Lawrence.Edwards@uct.ac.za

Robert Z. Lawrence

JFK School of Government

79 JFK Street

Cambridge, MA 02138

and NBER

robert_lawrence@harvard.edu 


\section{AGOA Rules: The intended and unintended consequences of Special Fabric Provisions.}

\section{Introduction}

The export performance of the small, land-locked nation of Lesotho is an African success story that demonstrates both the power and limitations of trade preferences. In 2004, just three years after Lesotho became eligible for preferences under the Africa Growth and Opportunities Act (AGOA) the clothing exports to the US from one of Africa's poorest land-locked nations had trebled to reach $\$ 460$ million and provide employment for over 50,000 workers (Bennett, 2006). The performance of Lesotho and several other preference recipients was particularly striking because it seemed to contradict the pessimistic verdict many had reached about Africa’s capacity to become a globally competitive exporter of manufactured products even when granted preferential market access. $^{2}$

On May 12 2010, a ceremony was held on Capitol Hill in Washington DC, to celebrate the tenth Anniversary of AGOA. In his remarks at the gathering, United States Trade Representative Ron Kirk credited AGOA with "a substantial increase in two-way U.S.-Africa trade since 2000, with African countries now exporting to the United States a more diverse range of value-added products,” Kirk also asserted that the trade program "powerfully demonstrates the link between trade and economic development.” ${ }^{3}$ In this paper we will provide some evidence that supports Kirk's

\footnotetext{
${ }^{2}$ Several studies have been devoted to explaining this poor performance, and most conclude that the problems lie with the African countries themselves, rather than on the access given their products in foreign markets. A host of inhibiting factors have been identified (Ng et al., 1996; Wang and Winters, 1998).

${ }^{3}$ http://www.america.gov/st/business-english/2010/May/20100513122443SztiwomoD0.8958856.html
} 
positive verdict: AGOA has stimulated exports of manufactured products, especially clothing, but we will also suggest that the ultimate impact on economic development has been quite disappointing. We will argue that both the success and limitations are the predictable consequences of the manner in which the preferences have been constructed. We will show that although these preferences encourage exports, they simultaneously create disincentives for local value-addition that may limit the program’s development benefits.

\section{Background}

As indicated by Mr. Kirk’s remarks, trade preferences are of interest not only because they might provide one time benefits in the form of higher incomes and increased employment but also because trade is associated with more dynamic benefits that lead to faster growth. Economic growth is an ever- expanding process in which actors not only replicate what they were doing on greater scale but continuously develop new capabilities that allow them to produce increasingly sophisticated goods and services (Hausmann, Hwang and Rodrik, 20007). More developed countries typically produce higher unit value products and wider ranges of products than their less-developed counterparts (Schott, 2004). These products often face less elastic demands and provide higher profit margins than more standardized, commodity-like products. If they can “learn by doing” by using trade preferences, it is hoped that firms that start by exporting a few simple products can upgrade their product sophistication, and diversify into other products and markets and ultimately become competitors that no longer need preferential treatment. ${ }^{4}$ In addition, it is

\footnotetext{
${ }^{4}$ According to Hwang (2007) there is unconditional convergence at the 6-digit level. If countries start to produce low unit-value goods within a product category, they will eventually experience significant increases in their unit values. The claim is that this will happen more or less automatically, without any special supportive policies in place.
} 
hoped that there are benefits to the rest of the economy. Other domestic firms could gain too through backward and forward linkages as exporters demand inputs and services and become increasingly embedded in the local economy.

During the industrial revolution this form of development was evident in the textile industry which was an important driver of industrialization. Japan, and later Korea, Hong Kong and other dynamic Asians also all cut their teeth as exporters of clothing continuously upgrading, and diversifying (Gereffi, 1999). Motivated in part by such considerations, the EU and the US both implemented multilateral Generalized Special Preferences (GSP) programs in the 1970s. In addition, they both have regionally focused preferential programs. ${ }^{5}$

Yet, the notion that developed country markets are open to manufactured exports from least developed economies as a result of these concessions can be challenged. It is difficult for underdeveloped countries to produce complete complex products but they are often quite capable of providing simple assembly operations. Some of the preferences given through programs are thus a sham because they include rules of origin that require more local production than these poor countries can provide. These rules are generally justified as necessary to prevent the tradedeflection that could occur if products are imported from third countries and then, with little additional value added, claimed as originating from preference-recipients a practice sometimes known as “screwdriver plants.” This is a legitimate concern, but the rules are more constraining than strictly necessary and they inhibit poor countries

\footnotetext{
${ }^{5}$ The EU granted African, Caribbean and Pacific (ACP) Countries special preferences, first under the Lomé Conventions (starting in 1976) and later through the Contonou Agreement (2000). More recently the EU has concluded Economic Partnership Agreements (EPAs) with groups of ACP countries. The US has granted special preferences under the Caribbean Basin Initiative (CBI), the Andean Promotion Act and AGOA. Preferences for least developed countries (LDCs) have received special attention. In 2001, the European Union introduced an "Everything But Arms” (EBA) program which provides LDC exports duty free, quota-free access. In the Doha Round negotiations the United States agreed to give duty-free access to LDCs in 97 percent of its tariff lines.
} 
from specializing in the narrow slices of global production chains in which their comparative advantage is likely to lie.

In the case of preference programs in apparel, these rules are particularly stringent, generally requiring that at least two (in the case of the EU) or even (in the case of the US) three transformation processes (e.g. yarn, fabric, assembly) in the preference-receiving or granting countries to qualify for duty-free entry. (For an excellent account see Ahmad, 2007). These rules are especially problematic because fabric production is a highly capital and technology activity that is beyond the capabilities of most very poor countries.

The rules of the US AGOA program are however an important exception, indeed perhaps the exception that proves the rule. AGOA not only gave all SubSaharan countries extensive duty -free quota-free access to the US (Table 1). ${ }^{6}$ Its rules of origin also contained an unusual a waiver for wearing apparel that was granted to "Lesser Developed Beneficiary Countries” (LDBCs). Subject to a fairly generous market-share caps that have not been binding, the waiver allowed these LDBC countries to use third-country fabrics or yarn and still export clothing under the AGOA preferences. ${ }^{7}$ Instead of requiring individual items to meet specific transformation rules, such as minimum value-added requirements, or the use of domestic fabric, the US set up a simple inspection program that verified that genuine

\footnotetext{
${ }^{6}$ In May 2000, the US congress passed AGOA. The Act granted duty free access for 4600 GSP tariffline items plus another 1800 tariff line -items not on the original GSP. This meant that, aside from some apparel and agricultural products, AGOA beneficiaries could export almost any product to the US duty free. The AGOA preferences for garments required that that they are made of $85 \%$ US made yarn and fabric or from fabrics and yarns made in other AGOA beneficiary countries.

${ }^{7}$ Most of the countries that were eligible for the wainver are classified as Least Developed by the United Nations. Botswana and Namibia did not meet the requirements for the Special Rule as their GDP per capita exceed the minimum of US\$ 1500 in 1998. However, they were designated as LDC countries under amendments to the AGOA act in 2002 (AGOA II) and 2004 (AGOA IV). Mauritius was temporarily granted the third-country fabric derogation from October 2004-September 2005 under the Miscellaneous Tariff Bill of 2004 (known as AGOA III). More recently Mauritius qualified for the third-country fabric derogation in November 2008 for a period of 4 years.
} 
production activities were taking place. ${ }^{8}$ Although the special LDBC rule was originally scheduled to expire after three years, it was extended in 2004 for another three years and in 2007 for a further five.

[TABLE 1 HERE]

Countries not defined as "lesser-developed" such as South Africa and Mauritius did receive AGOA preferences, but they were required to meet GSP rules of origin that for clothing required the use of US or regional yarns or fabric. Because the different treatment for higher income countries provides a useful control group, AGOA provides an ideal opportunity to explore the role of different types of rules of origin in preferential arrangements. And the experience demonstrates how important they can be: US imports of clothing from AGOA countries (SITC 84- Apparel and Clothing Accessories) increased from \$730 million in 2000 to \$1755 million in 2004. This growth was dominated by US imports of clothing from the least developed African countries which increased by four hundred percent, almost all of which took advantage of the lesser developed country provision (See Figure 1). The largest growth in exports between 2000 and 2004 came from Lesotho (up from \$140 million to $\$ 456$ million) and over the same period very significant increases also occurred in Kenya (up from \$43 million to \$270 million), Madagascar (\$110 million to \$323 million), Swaziland (\$32 million to $\$ 179$ million) and Namibia (0 to $\$ 79$ million) (Figure 2). By contrast in 2004, US imports of clothing from South Africa and

\footnotetext{
${ }^{8}$ AGOA privileges also require protecting US intellectual property rights, observing labor rights, proving access to US trade and investment and implementing rule of law. Apparel exports require adopting an effective visa system to prevent transshipment
} 
Mauritius, the two largest African clothing exporters when AGOA was passed, were actually 18 million dollars lower than they had been in 2000 (Figure 2).

[FIGURE 1 \& 2 HERE]

AGOA also stimulated entry into new clothing markets. Table 2 reports the number of HTS ten-digit apparel products produced by AGOA countries. Overall AGOA countries export limited ranges of apparel products. South Africa, Mauritius and Madagascar had the widest range of products (over 130 each) prior to the implementation of AGOA in 2000. AGOA preferences increased product penetration. Many countries experienced exceptional increases in the total number of lines from 2000 to 2004 (see Kenya from 45 to 155, Swaziland from 47 to 139, Lesotho from 60 to 118 ). ${ }^{9}$ In most countries however these trends reversed after 2005, but still remained above 2000 levels.

[TABLE 2]

AGOA countries have experienced setbacks, however, first when the constraints on their (mainly Asian) competitors were lifted with the expiration of the Multi-Fiber Arrangement in 2005 and second with the slump in the US because of the global financial crisis. ${ }^{10}$ As a result, U.S. imports declined, although for the least developed AGOA countries still remained three times as large as in 2000. By contrast,

\footnotetext{
${ }^{9}$ The largest contractions in Lesotho occurred in firms producing knitted garments; those producing woven garments (e.g. denim) did better. See Bennet op. cit.

${ }^{10}$ In July 2007 Lesotho Clothing and Applied Workers Union estimated employment at 44,000 compared to 55,000 in 2004.
} 
despite AGOA, imports from South Africa and Mauritius combined were decimated and in 2008 were only a third of their 2000 levels.

Several research papers have confirmed what is obvious to the naked eye -that the lesser developed country provisions have played a key role in the outcomes. Using a variety of methodologies, empirical estimates confirm that preferences under AGOA are a significant determinant of Apparel exports: Mattoo, Devesh, and Subramanian (2003) stressed the role of rules of origin in limiting the overall benefits from AGOA to all recipients. Collier \& Venables (2007) find that the AGOA apparel provision had a positive and significant effect. Frazer and Van Biesebroeck (2010) find that the AGOA had a "large and robust effect that grew over time" and estimate that overall AGOA apparel exports increased by 53 percent with stronger impacts on products with high initial levels of protection. Portugal-Perez (2008) report an impact of 96 percent for 22 countries eligible for the third-country fabric provision, and 303 percent for the top 7 beneficiaries ${ }^{11}$ In addition to higher export volumes there is also evidence that AGOA exporters enjoyed higher prices and captured some of the tariff rents created by the preferences (Olarreaga and Özden, 2005). Apparently, whatever Africa's handicaps, they have not prevented substantial responses: indeed, there is no evidence of differential effects in taking advantage of AGOA based on measures of corruption or institutional quality (Frazer and Van Biesebroeck, 2010).

Despite the impressive growth in volumes, there is also some disquieting evidence in AGOA's performance that relates to the issue of dynamic benefits. Decompositions of output growth reported in Table 3 reveal that the export of new product lines (the extensive margin) contributed only 30 percent of total AGOA import growth from LDC special rule countries between 2000 and 2004, and 42

\footnotetext{
${ }^{11}$ Other studies include Brenton and Ikezuki (2005), Gibbon (2003), Seyoum (2007), Nouve (2005), Rolfe and Woodward (2005), FIAS (2006).
} 
percent of the decline from 2004-08. Strikingly only 8 percent of the growth in Lesotho's apparel exports took the form of new products. The share of product lines accounted for by the top four and top ten HS 10-digit products is around sixty and eighty percent and has remained fairly constant throughout the period. In addition, production is predominantly CMT (Cut-Make-Trim) with little value addition and there is little evidence of dynamic spillovers to other sectors of the economies (Lall 2005). These trends are exemplified by the development of Lesotho's clothing industry in response to the AGOA preferences. Therefore, before presenting and testing a theory that can explain these outcomes, we describe briefly the history of Lesotho’s clothing industry.

[TABLE 3]

Lesotho

As the largest apparel exporter to the US, Lesotho is of particular interest. Whereas some countries such as Namibia, Malawi and Botswana, became clothing exporters for the first time after AGOA, the response of Lesotho actually built on a longer historical experience in which trade preferences and policies also played an important part. The industry was launched in the 1980s when Taiwanese manufacturers, originally based in South Africa, moved to Lesotho in order to avoid trade sanctions imposed by the US and Europe on what was then the Apartheid regime. More investors were attracted in the late 1980s, after the European Union signed the Lomé convention, which granted special preferences to the ACP countries that had formerly been colonies. While the clothing preferences in Lomé had a double transformation rule, Lesotho was granted a temporary derogation from the 
requirement allowing it to use third country fabrics that the investors took advantage of.

When the derogation expired in the mid 90s, exports to Europe plunged and they have never recovered (Figure 3). This experience provided the first demonstration of the importance of the role of these special preferences in the viability of Lesotho's exports of clothing. Clothing exports to the United States were subject to tariffs but were also constrained by quota restrictions under the MFA. As these became increasingly binding on others, Lesotho’s foreign owned firms shifted to exporting to the United States to take advantage of its unfilled quotas. Lesotho's concentration of exports in products where quota constraints on Chinese exports were binding is clearly revealed in Figure 4. Thus even prior to the passage of AGOA, firms based in Lesotho, most of which were subsidiaries of Asian multinationals were exporting to the US. Indeed, after 1999, 99 percent of all Lesotho’s apparel exports went to the US with only $0.8 \%$ going to South Africa and just $0.2 \%$ to the EU.

\section{[FIGURE 3]}

The small share of Lesotho's exports going to South Africa also indicates the important role played by fabric rules of origin. The US MFN tariff on clothing is around 17 percent, while the SACU tariff is about 40 percent. Thus garments exported to South Africa from Lesotho (which is within the customs union) have a much larger margin of preference. Yet Lesotho is far more competitive in the US than in SACU. ${ }^{12}$

\footnotetext{
${ }^{12}$ Indeed according to Sandrey et al. (2005) Lesotho cannot even compete in Lesotho! "Examination of the local clothing retail outlets reveals a predominance of both Chinese and South African garments.”
} 
The reason is that to sell in South Africa, Lesotho has to pay SACU tariffs or SACU

prices for fabric. By contrast, under AGOA it obtains these duty free. ${ }^{13}$

[FIGURE 4]

AGOA has been in effect for a decade but there is little evidence that much of Lesotho's industry could survive without preferences or that it has diversified horizontally into new products and markets or vertically into greater domestic value addition. Factories in Lesotho continue to concentrate on just a narrow range of garments: the most basic low unit value categories knitted tee-shorts, slacks, blouses and blue-jeans. The slice of the production chain they participate in is narrow and does not seem to be expanding. Most apparel manufacturing in Lesotho is CMT (CutMake-Trim). The firms, almost entirely foreign owned, typically provide assembly, packaging and shipping services and depend on their Asian headquarters to generate orders, design the clothes and send them the fabric they need. This can be seen by comparing the industry wage bill for 50,000 workers (approximately $\$ 1000$ per worker) i.e. \$50 million in 2004 with total US exports valued at \$456 million. Most of the value is thus added to other parts of the chain. Almost none of the managers are locals and the buyers of fabric and the marketers of the garments and the key strategic corporate decisions are all made thousands of miles away in Asia.

\footnotetext{
${ }^{13}$ To be sure, factors besides favourable rules of origin have contributed to Lesotho's performance. (Maloney, 2006) These include fluctuations in the Rand to which its currency is tied (favourable between 2000 and 2002) and other policies to assist exporters by the Lesotho Government. In addition Lesotho has benefited from a favourable international image as a non-sweatshop producer (Seidman 2009). It has also been promoted by Bono in his campaign against Aids. The Lesotho National Development Corporation (LNDC) has played an active role, offering favourable rents for factory shells. The government also provided generous tax treatment from the Government --reduced from 15 to 0 in 2006 - and sought to maintain industrial peace with a Directorate of Dispute Prevention and Resolution. The Government has used the Duty-Credit-Certificate Scheme of the South African Customs Union that gives apparel firms between 10 and 25 percent of the FOB value of their exports in certificates which allow them to import textiles or apparel duty-free.
} 
The local production process is characterized by highly routine steps used to produce very large volumes. Just one buyer -- the US retailer the GAP -- accounts for almost 40 percent of overall output. The combination of the large scale on which they operate and the large orders by concentrated buyers, makes it difficult for small firms to enter the market. In addition, to move up the value chain and to produce differentiated products in smaller batches requires more skilled workers. This is part of the explanation for Lesotho's inability to do well in the relatively small South African market in which demand is more varied.

One firm in Lesotho has built a denim plant. ${ }^{14}$ But with this exception, all fabrics are imported. Lesotho and other AGOA countries, even South Africa, therefore, lack the domestic textile industry that would allow them to meet the regular clothing rules of origin in US preference programs.

Lesotho's workers have relatively low productivity levels and their skills do not appear to have increased over time. ${ }^{15}$ Lall ascribes the lack of improvement in part to the Labor Code Rule that prohibits the use of piece rate. He noted "Despite a decade and a half or experience in CMT operations, productivity in Lesotho is below that of major competitors. Since wages are comparable, its competitiveness cannot outlast trade privileges” (Lall 2005).

The relatively low quality of Lesotho's (and other AGOA) apparel exports is also revealed in the comparative price of its exports. Table 4 presents the average unit values of the top 15 apparel products at HS 10-digit level exported by Lesotho to the US in 2004. These unit values are compared against the average unit value of other

\footnotetext{
${ }^{14}$ In 2004 the industry faced a major challenge which the potential expiration of the special rule. Partly anticipating the expiration of the Special Rule in 2004, the Nien Hsing Group of Taiwan invested over $\$ 100$ million to build the Formosa Mill, a state of the art denim fabric mill.

${ }^{15}$ Lall (2005) estimated that while Lesotho’s wages were similar to Asian levels, its productivity was typically only fifty percent of East Asian levels. According to Morris and Sedowski (2006), worker productivity has not increased over a ten year period. See also Morris (2006).
} 
lesser-developed AGOA countries and the $10^{\text {th }}, 25^{\text {th }}$, median, $75^{\text {th }}$ and $90^{\text {th }}$ percentile unit values of the 226 countries in the sample. In all but one case when it is just below the $25^{\text {th }}$ percentile, the unit values of Lesotho's apparel exports fall between the $25^{\text {th }}$ and $50^{\text {th }}$ percentile range.

\section{[TABLE 4]}

What is also striking is the range of unit values even within these highly disaggregated product lines (see Schott 2004). For example, the $90^{\text {th }}$ percentile unit value of a dozen women's or girls' cotton pullovers (Lesotho's top apparel export) in 2004 was 280 dollars versus 31 dollars for Lesotho exports.

The combination of a productivity disadvantage and almost no domestic textile industry makes the industry's survival totally dependent on its preferences. Each time the expiration of the special rule has drawn near, therefore studies have issued credible and dire warnings about the industry’s ability to survive without them (Salm, 2002 and Bennett, 2006).

This experience makes it clear that trade need not automatically lead to growth and the manner in which trade is stimulated could well prove consequential for the amount and nature of the growth it stimulates. In particular it suggests that trade that is stimulated by preferences might well have different effects than trade that occurs for other reasons.

Why this disappointment? Both Lall (2005) and Collier and Venables (2007) suggest it may be that these AGOA countries are simply too underdeveloped for the exports to ignite the process. Collier and Venables argue it reflects a lack of complementary inputs that are required to exploit scale economies. They suggest that 
preferences are only likely to work if countries already have "the skills and infrastructure to be near the threshold of global manufacturing competitiveness" (P1328). Lall also suggests that part of the explanation could lie with having foreign factory owners - most of whom are Taiwanese, -- that are not closely integrated into the local community. Ironically, this might suggest that these kinds of preferences should be given to the more advanced developing countries like South Africa rather than the least developed countries that have received them.

In this paper, however, we will explore a different explanation that has been overlooked in the literature. We will argue that both the positive and negative responses to AGOA are no accident. Indeed, they are the consequences that economic theory would lead us to expect, given the form in which the preferences have been granted.

As we will show using the theory of effective protection, preferences combined with the third country fabric rule can have powerful financial effects. They could easily be the equivalent of a subsidy to production that is two or three times higher than the 17 percent preference margin granted by AGOA through MFN tariff relief on clothing. This allows AGOA producers to offset cost disadvantages due to the lower productivity of their workers and greater distance from suppliers and markets and helps explain why the initial responses to AGOA (and the availability of unused MFA quotas) were so powerful.

On the other hand, in theory the preferences also have two deleterious effects. First, they steer firms mainly toward the simplest products in which clothing producers add little value. Thus the preferences tax skills acquisition and discourage firms from moving up the value-chain. Second, the preferences (and the MFA) discourage backward linkages because they induce exporters to use relatively 
expensive fabrics rather than the cheaper fabrics that are more likely to be produced in poor countries.

In sum, trade preferences “work.” They can stimulate trade, raise incomes in developing countries and boost employment. But whether they actually lead to development conceived of as a cumulative growth process is much less certain.

In addition changes in other trade policies at first helped and then hindered AGOA's performance. On the one hand, the MFA initially provided an especially favorable environment for AGOA countries to produce low unit value products because it not only constrained their Asian competitors but also induced these exporters to shift towards higher quality products. On the other hand, when the MFA was removed, constrained countries such as China moved strongly into precisely the markets in which AGOA countries had specialized. Although AGOA helped the least developed African countries withstand this shock, they were nonetheless adversely affected.

This paper proceeds now in three sections. In the first we discuss the economic theory of the effects these regimes are likely to have. In the second, we conduct several empirical tests of the theory and in the final section we present our conclusions.

\section{Theory}

The overview of Lesotho's export performance identified the influence of two trade policies: (i) the effect of MFA quotas and their removal and (ii) the effect of AGOA tariff preferences and rules of origin. In this section we draw on economic theory to investigate the impact of these policies. The focus is on incentives they create for the production and export of particular types of clothing products. We are particularly 
interested in the impact on product characteristics such as quality, fabric-use and value addition in recipient countries.

We will show that the regime governing clothing trade can be expected to have a profound impact on clothing production choices in countries like Lesotho. In particular, we will demonstrate that the MFA not only provided a subsidy to Lesotho's clothing exports but also created incentives for it to specialize in low quality and low valued-added products. The AGOA program provided an even more powerful incentive to expand exports of low value added clothing products, but it had an additional effect. The third-country fabric provision encouraged further specialization in clothing products with high fabric cost shares.

Some of the arguments we will use are not new. The body of literature on how trade policies influence product characteristics is well established in the case of quotas (Falvey, 1979; Krishna, 1987, Feenstra, 1988) and transport costs (Alchian and Allen, 1964; Hummels and Skiba, 2004). The central result in this literature is that quotas and unit transport costs lead to quality upgrading, while tariffs do not. However, the literature generally assumes integrated production, and less studied are the effects of quotas and tariffs on the quality and value-addition when products contain imported intermediate inputs. This analysis therefore explores how tariff preferences and their associated rules of origin lead to changes in the quality of goods produced and exported. We focus on clothing and fabric inputs although some of the results would be applicable to other products that are manufacturing with imported intermediate inputs.

Most apparel firms located in Lesotho sell products to the U.S. through 'full package' intermediaries located in East Asia. These 'full package' suppliers compete with others for orders in the US and Europe (Lall, 2005). They then contract these out 
to their associated apparel producers, either through competitive bidding or through some allocation rule. Lesotho, for example, will export all products for which its production costs are lower than its competitor suppliers.

We are therefore going to develop a simple model which captures this intrafirm allocation and thus the relative shares of two countries, think Lesotho and China, in the US apparel imports. We model clothing as an array of products containing varying quantities of labor and fabric inputs. We determine patterns of value-addition and specialization in a Ricardian framework that captures the effects of differences in fabric intensity. We then explore the effects of changes in market access policies on production choices in both countries. In particular we highlight how these policy changes affect both the volumes (intensive margin) and the types of products (the extensive margin) each of the countries will export.

\section{Model}

We assume apparel products are differentiated by type of product and the content of fabric. ${ }^{16}$ Each apparel product $z$ is associated with a point on an interval $[0,1]$ and is assembled using labor and fabric according to a constant returns to scale Leontief production function: ${ }^{17}$

$$
y(z)=\min [L(z) / a(z), F(z) / \theta(z)]
$$

\footnotetext{
${ }^{16}$ Mattoo et al. (2003) develop an alternative model with decreasing returns and infinite demand to show how both tariff preferences and waivers of rules of origin increase exports of existing products. They do not deal with the impact on product quality, nor export of new varieties.

${ }^{17}$ Portugal-Perez (2008) assumes a similar production function. A clear limitation of this model is that it does not take into account capital (sewing machines, fabric cutters, irons, washing and drying machines) used in the production of apparel. However, in a world where this type of capital is internationally mobile, it is the non-traded factors that become the primary determinant of a country's comparative advantage (Wood and Mayer, 2001).
} 
$a(z)$ is the labor used per unit output, $L(z)$ is the quantity of labor, $F(z)$ is the quantity of fabric and $\theta(z)$ is the unit fabric requirement in square meters (the input-output coefficient).

Using the cost function dual to the production function, the unit cost $c(z)$ of clothing (assuming no transport costs) is given as:

$$
c(z)=a(z) w+\theta(z) P F(z)
$$

where $w$ is the wage and $P F(z)$ is the price per square meter fabric associated with product $z$. We also assume firms are competitive, so equilibrium profits are zero and the free on board price equals costs, i.e.

$$
p(z)=c(z)=a(z) w+\theta(z) P F(z) .
$$

Products are therefore differentiated according to their unit labor requirements, as well as unit fabric costs which are affected by the quantity and price of fabric used. For example, we would expect more complex apparel products (e.g. suits) to require more labor than simple products (e.g. T-shirts). Although we do not model quality specifically, we would also expect higher quality apparel to require more labor services and higher priced fabric than lower quality products.

The allocation decision

The allocation process depends on the relative cost of production across different locations. Lesotho will export all products for which its costs are less than or equal to those from China. This allocation condition can be specified as:

$$
a(z) w+\theta(z) P F(z) \leq a^{*}(z) w^{*}+\theta(z) P F^{*}(z)
$$

where transport costs are assumed to be zero and * denotes foreign competitor (China). Under free trade where fabric is internationally traded and there are no 
differences in unit fabric costs $\left(P F(z)=P F^{*}(z)\right)$, we can re-specify the relationship in terms of Lesotho's Relative Unit Labor Cost (RULC):

$$
\operatorname{RULC}(z)=\frac{w a(z)}{w^{*} a^{*}(z)} \leq 1
$$

Here, home (Lesotho) exports all apparel products for which its unit labor costs are lower than its foreign competitors. Alternatively, China exports all apparel products for which its relative wages are less than or equal to its relative productivity.

This result implies that comparative advantage when intermediate inputs can be obtained at world prices is entirely dependent on the relative effective price of the non-traded factor. This outcome is equivalent to that of the Dornbusch, Fischer and Samuelson (DFS) (1977) Ricardian model with a continuum of goods. The fabric content of apparel therefore has no influence on what is produced by the home country. We will see later that this no longer holds once we introduce quotas and preferential trade barriers.

\section{Consumption and Equilibrium}

To close the model, we assume that there is no US apparel production, that countries only export apparel to the U.S. and that U.S. consumers have identical and homothetic preferences. Utility is Cobb-Douglas for a numeraire good (non-clothing products), but is a constant elasticity of substitution (CES) function in the quantities of the differentiated clothing products. The utility function is specified as: ${ }^{18}$

$$
u=\left(\int_{0}^{1} C^{\rho}(z) d z\right)^{\alpha / \rho} C_{0}^{1-\alpha} \quad 0<\rho<1
$$

where $C(z)$ denotes total U.S. consumption of apparel products $z$ and $C_{0}$ is consumption of all other goods. U.S consumers spend a constant fraction $\alpha$ of their

\footnotetext{
${ }^{18}$ See Dixit and Norman (1980: 282).
} 
income on apparel products with the remainder spent on the numeraire good. In addition, the differentiated apparel products are substitutes with a constant elasticity of substitution given by $\sigma=1 /(1-\rho)>11^{19}$

Since $u$ is a separable utility function, the optimal choice of apparel products can be obtained by maximizing the CES component of the utility function subject to expenditure being less than or equal to $\alpha I$ where $I$ is U.S. income. Optimal demand by U.S. consumers for each product $z$ is given by

$$
C(\mathrm{z})=\left(\frac{p(\mathrm{z})}{P}\right)^{-\sigma} \frac{\alpha \mathrm{I}}{P}
$$

where the price index of the CES quantity index is given by $P=\left(\int_{0}^{1} p(z)^{1-\sigma} d z\right)^{1 /(1-\sigma)}$.

A rise in the relative price of a particular product will therefore result in a disproportionate reduction (as $\sigma>1$ ) in the relative consumption of that product. ${ }^{20}$ Assuming a sufficiently large number of products, the elasticity of demand for each product will be given by $\sigma$.

The model so far differs importantly from the Dixit/Stiglitz (1977) and Krugman (1979, 1980) monopolistic competition models in that we assume perfect competition and constant returns to scale. The full range of apparel products will therefore be produced and prices will equal marginal cost in equilibrium. ${ }^{21}$ In

\footnotetext{
${ }^{19}$ Note that this is ensures that the differentiated goods are closer substitutes among themselves than are the differentiated goods and the numeraire good. We do not modify the CES function to allow for quality as in Hummels and Klenow (2005). A quality index acts as a demand shifter, leading to higher consumption at every given price.

${ }^{20}$ To see this take the ratio of (6) for product 1 to product 2 to obtain: $C\left(z_{1}\right) / C\left(z_{2}\right)=\left(p\left(z_{1}\right) / p\left(z_{2}\right)\right)^{-\sigma}$.

${ }^{21}$ While we could follow DFS (1977) and use a Cobb-Douglas utility function for U.S. consumers, this has the disadvantageous outcome that the value of U.S. imports of each variety does not change.

Growth in foreign exports to the US can only be achieved through growth along the extensive margin. This outcome is inconsistent with the empirical evidence.
} 
addition, the value of exports of any product decline in response to a rise in relative prices, with a greater change the more substitutable are the differentiated products:

$$
p(z) C(z)=\left(\frac{p(z)}{P}\right)^{1-\sigma} \alpha I
$$

The final condition for equilibrium is that labor demand equals labor supply $(L)$, or alternatively that labor income equals the wage bill in the clothing sector. Assume that apparel products are indexed according to diminishing Chinese relative unit labor requirements, $\left(a^{*}(z) / a(z)\right)$. With $\bar{z}$ denoting a hypothetical dividing line between Chinese exports $(0, \bar{z})$ and Lesotho exports $(\bar{z}, 1)$, the home and foreign labor market clearing condition are respectively represented as:

$$
w L=\int_{0}^{\bar{z}} w a(z) C(z) d z
$$

and

$$
w^{*} L^{*}=\int_{\bar{z}}^{1} w^{*} a^{*}(z) C(z) d z
$$

Taking the ratio of these two conditions gives:

$$
\frac{w}{w^{*}}=\left(\frac{\int_{0}^{\bar{z}} w a(z) C(z) d z}{\int_{\bar{z}}^{1} w^{*} a^{*}(z) C(z) d z}\right)\left(\frac{L^{*}}{L}\right)
$$

This schedule is upward sloping on $z$. A rise in the range of products exported by Lesotho at constant relative wages increases the demand for labor in Lesotho and reduces the demand for labor in the competitor country. This raises the relative wage in Lesotho required to equate demand and supply of labor. Equilibrium is achieved through reductions in relative U.S. consumption of Lesotho exports in response to higher prices. 
If relative wages are fixed, as may be expected in Lesotho where unemployment is very high, then the adjustment to equilibrium will be through changes in the relative employment of labor in the apparel sector ( $L * L$ falls). In what follows, we impose the fixed wage assumption to avoid unnecessary complexity associated with the marginal effect of relative wage changes on the range of products exported. Together, equations (2), (3), (6), (7) (8) and the price index solve for Chinese and Lesotho wages, the geographic specialization of apparel exports, the price index $P$ and U.S. consumption and prices across the full spectrum of products. Quotas and product choice for exporting firms

The MFA was important in the markets in which Lesotho and other clothing producers operated and its application and elimination had major effects (Harrigan and Barrows, 2009). Quotas on clothing imports into developed economies were widely applied under the MFA with imports from China particularly constrained (Brambilla, Khandelwa and Schott, 2010). The MFA, therefore, led to a geographical dispersion of clothing production as producers re-located to countries where there were unused quotas. Lesotho (and other AGOA countries) was a beneficiary of this relocation of production as its US quotas were not filled. ${ }^{22}$ But the effects on clothing products were not all the same. As we will argue, quotas under the MFA induced the export of low value added, fabric-intensive and low priced (low quality) clothing products in developing countries such as Lesotho.

It is well established in the literature that under competitive conditions a quota is equivalent to a specific tariff (Falvey, 1979). The result also holds in cases of

\footnotetext{
${ }^{22}$ For data on quota fill rates see the US Office for Textiles and Apparel (OTEXA) (http://otexa.ita.doc.gov/). Brambilla et al. (2010) provide a review of the fill rates for various countries since the 1980s.
} 
imperfect competition (Feenstra 1988, 2004). ${ }^{23}$ While the quota restricts the total volume of sales, its effect differs across products produced by the firm. Firms adjust exports of different products to ensure that they earn the same quota premium from each good exported (Feenstra, 2004). The effect is that exports of low priced (low quality) products are the most adversely affected.

We find similar effects in our model. Assume apparel quotas are imposed on imports from China. The specific tariff effect of the quota (denoted as $s$ ) alters the allocation condition (equation 3) that determines the range of apparel products exported by Lesotho. The condition becomes:

$$
a(z) w+\theta(z) P F(z) \leq a^{*}(z) w^{*}+\theta(z) P F^{*}(z)+s .
$$

Assuming, for exposition purposes, that both Lesotho and China have access to fabric at world prices $\left(P F^{*}(z)=P F(z)\right)$, this equation can be re-specified in terms of Lesotho’s Relative Unit Labor Cost (RULC): ${ }^{24}$

$$
\frac{w a(z)}{w^{*} a^{*}(z)} \leq 1+\frac{s}{a^{*}(z) w^{*}}
$$

Further, if we let $\lambda^{*}(z)$ denote the share of fabric in foreign costs $\left(\lambda^{*}(z)=\theta(z) P F^{*}(z) / c^{*}(z)\right)$ and therefore $1-\lambda^{*}(z)$ as unit labor costs as a share of total costs $\left(=w^{*} a^{*}(z) / c^{*}(z)\right)$, we can simplify the allocation condition even more to:

$$
\frac{w a(z)}{w^{*} a^{*}(z)} \leq 1+\frac{s}{\left(1-\lambda^{*}(z)\right) c^{*}(z)} .
$$

\footnotetext{
${ }^{23}$ See Krishna (1987) for an imperfect competition model where firms jointly select the quantity and the quality of the products they export in response to a quota. Feenstra $(1988,2004)$ also show how quotas lead to an upgrading of the characteristics within each variety produced.

${ }^{24}$ In Lesotho, for example, import duties were rebated on imported fabric used in the production of apparel exports. We ignore the effects that transport cost differentials have on the relationship. Specific transport costs on output can be modelled in an equivalent way to the effect of specific tariffs and quotas. For example, relatively high specific transport costs on output for the competitor country have the equivalent effect on quality as our example for quotas. See Falvey (1979) and Hummels and Skiba (2004).
} 
The effect of the quota is a modified allocation condition in which the right hand side of the DFS equation (4) is raised by the term $s /\left(1-\lambda^{*}\right) c^{*}$. This term is positive and rises if, ceterus paribus, $s$ increases, costs fall or the share of fabric in production rises.

We can consider four implications of quotas under the MFA for apparel exports from Lesotho using this relationship. ${ }^{25}$ Firstly, the effect of a quota is equivalent to a specific subsidy on exports from non-quota constrained countries such as Lesotho. This enables Lesotho's producers to export apparel products even if they do not have a comparative advantage in the production of that product, i.e. where their RULC exceeds 1 by up to $s /\left(1-\lambda^{*}(z)\right) c^{*}(z)$. The implicit subsidy conferred by the tariff compensates the relatively inefficient apparel producers for their high relative unit labor costs and helps explain why countries such as Lesotho exported apparel under the MFA despite productivity levels that were lower and wage levels that were comparable to those of Asian levels (Lall 2005).

The second consideration is that the implicit subsidy of the quota for Lesotho (and other non-quota constrained countries) is a greater percent of the overall value the lower is the price $\left(c^{*}(z)\right)$ of the product exported by China. This is the standard result for quotas obtained by Falvey (1979). Quota constrained countries upgrade quality of exports by shifting to higher priced varieties. What we show here is that the

\footnotetext{
${ }^{25}$ There are two additional considerations. Missing from this story is the fact that within-quota tariffs were also imposed under the MFA. As shown by Hummels and Skiba (2004), ad valorem tariffs lower the relative demand for high-quality goods in the presence of per unit transport costs (or equivalently quotas). As tariffs rise, the shadow price of the quota constraint falls and dampens the effect (but not direction) of the quota on relative demand for high-quality products. The final consideration is that import quotas administered by the Office of Textiles and Apparels (OTEXA) are specified in terms of yardage of fabric equivalents and not quantity of goods. In this case, the quota is equivalent to a specific tariff on the price per square meter of fabric equivalence, i.e. the allocation condition is: $c(\mathrm{z}) / \theta \leq c^{*}(\mathrm{z}) / \theta+s$. The implication for Lesotho is that relative demand and relative prices shift in favor of exporting low priced clothing varieties that are intensive in the use of cheap fabric.
} 
gap in the market is filled by non-quota constrained countries that may not have been able to compete prior to the quotas, i.e. where their RULC exceeded 1.

The third consideration is novel to our model. Holding costs constant, the effective subsidy, i.e. the subsidy as a proportion of value added, rises exponentially with the share of costs (of the efficient producer) attributed to fabric. Alternatively, the effective subsidy is greater the smaller the value added of the product.

Take for example, two apparel products each priced at US\$10, but differing in terms of fabric-intensity: Fabric costs make up 90 percent of the cost of product A and 1 percent of the cost of product B. Assume further that the specific tariff equivalent of a quota on imports from China is 1 dollar. The resulting effective export subsidy for Lesotho is just over 1 percent for product B, but is 100 percent for product $\mathrm{A}$. In fact, the effective subsidy is 100 percent for any product in which China's labor costs are equal to 1 dollar. The implication is that firms in Lesotho will be able to compete in exporting product B, even if their unit labor costs are 100 percent higher than those of the competitive quota constrained supplier (China). These considerations explain how the quotas enable an expansion in the range of products exported by Lesotho and other non-quota constrained countries, i.e. growth along the extensive margin.

The impact of the quota is to shift the Chinese out of low prices products. This implies that relative price increase of Chinese exports will be strongest in low priced products. This leads to the fourth effect: Lesotho will also experience growth in the volume and value of existing exports (intensive margin) as the relative price of their existing exports falls relative to the exports from quota constrained countries (their export price falls relative to the average price index, see equation 6).. Therefore in Lesotho we expect the strongest intensive margin growth in exports in existing low 
priced products. In contrast, quota constrained countries experience a decline in the range, value and volume of their exports, particularly in low priced products.

In conclusion, we expect four effects of the MFA on Lesotho and other AGOA countries (and other non-quota constrained countries): a rise in the export of both (i) existing and (ii) new apparel products combined with specialization in (iii) cheap low quality products with (iv) very little value addition. The removal the MFA would have had the opposite effects. Previously quota constrained countries would shift production towards cheaper products with lower labor value added. Unconstrained countries would thus be especially adversely affected in these shifts, both in terms of the range and value of their apparel exports.

\section{Tariff preferences and product choice}

We now turn to an analysis of the effect of the tariff preferences granted under AGOA. Generally, theory suggests that in a competitive market ad valorem tariffs have no impact on value-addition as they preserve relative prices faced by the firm and the consumer (Falvey, 1979; Feenstra 1988). ${ }^{26}$ This changes once we introduce tariffs and tariff preferences in a model where products contain internationally traded intermediate inputs such as fabric.

Once tariffs are introduced, what determines whether Lesotho exports product $y(z)$ is whether the tariff inclusive price of its good in the US market is less than or equal to its foreign competitor, China: ${ }^{27}$

$$
c(z)(1+t) \leq c^{*}(z)\left(1+t^{*}\right)
$$

\footnotetext{
${ }^{26}$ Krishna (1987) presents an imperfect competition model where the firm’s choice of output and quality is influenced by ad valorem tariff rates.

${ }^{27}$ To simplify the model we have assumed that the ad valorem tariff does not vary by variety. Apparel tariffs actually vary enormously according to the type of fabric used and in some cases according to the quantity and amount of fabric used in production. Extending the model to allow for variation in tariffs across $z$ does not alter the main insights of the theory.
} 
Letting $\phi(z)$ denote the Lesotho fabric price relative to the Chinese fabric price, $P F(z) / P F^{*}(z)$, we can express the allocation condition (13) in terms of relative unit labor costs (RULC) and fabric cost shares $(\lambda)$ as follows:

$$
\frac{w a(z)}{w^{*} a^{*}(z)} \leq \frac{\left(1+t^{*}\right)}{(1+t)}+\frac{\lambda(z)}{1-\lambda(z)}\left[\frac{\left(1+t^{*}\right)}{(1+t)}-\phi(z)\right]
$$

The cut off point defining what products will be exported by Lesotho is now a function of relative tariff rates faced, fabric-intensity and relative fabric prices. To explore the implications for product choice under AGOA, three different scenarios are compared:

(a) Case 1: Pre-AGOA with MFN tariffs and competitive input supplies,

(c) Case 2: AGOA tariff preferences for LDC Special Rule beneficiaries, (d) Case 3: AGOA tariff preferences for non-LDC Special Rule beneficiaries

Case 1: No preferences, MFN tariff rates $\left(t=t^{*}\right)$ and access to competitively priced inputs

In the first scenario the US imposes common MFN tariffs on apparel imports from Lesotho and China. For MFN trade there are no rules of origin requirements or restrictions on access to internationally priced fabric, so barring domestic restrictions on use of inputs, all countries have access to internationally priced fabric, i.e. $(\phi(z)=1)$.

In this scenario, the product allocation condition 14 reduces to the standard RULC condition of the DFS model (equation 4). Tariffs affect both countries equivalently and the unit fabric cost components cancel each other out. The geographic location of production is determined entirely by relative unit labor costs, with specialization according to comparative advantage. Fabric intensity has no 
bearing on what a country exports. Tariff protection in this scenario introduces no fabric-use bias.

\section{Case 2: Preferential access granted to home $\left(t=0, t^{*}>0\right)$ and no rules of origin}

The second scenario is set up to reflect the AGOA preferences granted to Lesotho and other LDBCs. These countries are granted a tariff preference into the U.S. $(t=0$, $t^{*}>0$ ), but under the LDC Special Rule are also able to use internationally competitive third-country fabric in the production of apparel exports. Given our assumption of notransport costs, fabric prices are therefore equal in Lesotho and China $((\phi(z)=1)$.

The allocation condition in this case simplifies to:

$$
\frac{w a(z)}{w^{*} a^{*}(z)} \leq\left(1+t^{*}\right)+\frac{\lambda^{*}(z)}{1-\lambda^{*}(z)}\left(t^{*}\right)
$$

What can be observed from the relationship is that the effective preference is a function of both the tariff preference as well as the ratio of fabric cost shares to value added costs shares $\left(\lambda^{*} /\left(1-\lambda^{*}\right)\right)$. We explore the implications of this in more detail.

Take a scenario where apparel products contain no fabric, i.e. $\lambda^{*}=0$, and the term on the far right of equation 15 falls away. The tariff preference has a uniform impact on all apparel products and allows Lesotho to export products in which it is up to $1+t^{*}$ times less efficient at producing than China. For example, a tariff preference of 20 percent enables the home country to export new apparel products where its unit labor costs are up to 20 percent greater than their foreign competitors.

In addition to the export of new products (i.e. growth along extensive margin), the tariff reductions under AGOA also raise U.S. consumption of existing products exported by Lesotho (i.e. the intensive margin) through reductions in the relative U.S. consumer price of these goods. The effect on the volume and value of exports could 
be very large if products are highly substitutable. We would therefore expect to see growth in exports along both the intensive and extensive margin.

Once fabric is introduced, the AGOA preferences alter relative incentives to export products of different unit fabric contents. In particular, the tariff preference is greater for products with higher fabric cost shares. This is revealed by the second term on the right hand side which is positive and increasing (exponentially) in $\lambda^{*}$. As the fabric cost share approaches 1, the effective preference granted to Lesotho converges on positive infinity.

Diagrammatically, this relationship is represented in Figure 5. Assume for simplicity sake, that Lesotho's relative unit labor costs are fixed at $\left(a w / a^{*} w^{*}\right)_{1}$ on the vertical axes for all apparel products. We have also assumed that Lesotho's RULC exceeds 1 . On the horizontal access, apparel products are ordered according to rising fabric cost shares (or diminishing labor cost shares). In a competitive environment where Lesotho and China face the same U.S. tariffs (see Case 1 in Figure 5), Lesotho would not export any products as its RULC exceeds 1 . With tariff preferences plus waivers from the rules of origin granted to Lesotho, the relevant comparison is between RULC and the solid line (equals the right hand side of equation 15) identified as Case 2 in the Figure. Lesotho is still unable to export products with low fabric cost shares. However, because the effective tariff preference rises with fabric cost share, Lesotho is able to export all products in which the fabric cost share exceeds $\lambda_{1}$, despite having no comparative advantage in these products.

In sum, the tariff preference affects Lesotho’s exports in three ways. Firstly, it raises the relative unit labor cost threshold by $\left(1+t^{*}\right)$, which is equivalent to what we would expect in a tariff adjusted DFS model. Secondly, the threshold defining the cutoff-point is higher for fabric intensive products. This arises because tariffs not only 
tax foreign unit labor costs, but also tax the fabric content of the product. The total tariff equivalent preference per unit labor cost is therefore an increasing function of the unit fabric cost share. ${ }^{28}$ Finally, by reducing the relative price of exports, the preferences increase the volume and value of existing imports from beneficiary countries.

The implication for LDC AGOA beneficiaries is that they enter and specialize in the export of the most-fabric intensive apparel products. The AGOA preferences to LDC beneficiaries therefore compound the existing incentives to produce low value added or fabric-intensive products brought about by the MFA. There is one important difference. The AGOA incentives are unrelated to the price of the product, only fabric intensity whereas the implicit subsidy for non-quota constrained countries under the MFA is greatest for low priced fabric-intensive products.

[FIGURE 5]

Case 3: Preferential access granted to home $\left(t=0, t^{*}>0\right)$, but rules of origin constraints on fabric inputs

This scenario reflects the situation for non-LDC Special Rule AGOA countries such as South Africa (and Mauritius for most of the post 2001 period). Apparel exports from these countries have preferential access into the US market, but production is subject to a two-stage transformation requirement. Apparel producers from these countries are therefore required to use domestic (or U.S.) produced fabric in the

\footnotetext{
${ }^{28}$ In a small-country price taking model, the tariff effects are greatest for fabric intensive products even amongst those goods where it has a comparative advantage (the intensive margin). The tariff preferences therefore create incentives for firms to expand production most in the low value-added fabric-intensive varieties of products they are already exporting. In addition, the preferences would encourage entry of the least efficient firms into the most fabric-intensive apparel products.
} 
production of exports to the U.S. under AGOA preferences. If these countries produce fabric at internationally competitive prices, $\phi(z)=1$, then the outcome will be equivalent to Case 2. However, if local fabric is more expensive than foreign fabric, $\phi(z)>1$, the allocation condition is given by:

$$
\frac{w a(z)}{w^{*} a^{*}(z)} \leq\left(1+t^{*}\right)+\frac{\lambda^{*}(z)}{1-\lambda^{*}(z)}\left(1+t^{*}-\phi(z)\right)
$$

The relationship differs from equation 15 in that while the home country is granted a tariff preference, it has to utilize more expensive domestic fabric.

The impact on clothing production relative to the pre-AGOA period is ambiguous and depends on the fabric price disadvantage relative to the tariff preference. Take for instance a scenario (Case 3a) where the home relative fabric price disadvantage is less than the tariff preference such that $\left(1+t^{*}-\phi(z)\right)>0$. In this scenario, the effective preference rises with fabric-intensity, but less so than in Case 2. In Figure 5 this is depicted by the dashed line identified as Case 3a. The home country will export all products in which the fabric cost share exceeds $\lambda_{2}$.

An alternative scenario (3b) is one where the fabric price disadvantage is greater than the tariff preference such that $\left(1+t^{*}-\phi(z)\right)<0$. Here the effective preference declines as the fabric-intensity of the product rises. At some level of fabric-intensity, the fabric price disadvantage will dominate the tariff preference effect and reduce the right hand side of equation (15) to below 1. At this point, there is a disadvantage associated with exporting under the preferential access scheme as opposed to exporting under MFN rates (Case 1). Firms that are competitive in these products, i.e. RULC $<1$, will then export under MFN rates. In Figure 5, Case 3b depicts the declining effective preference (Case 3b), although in this example, the 
non-LDC AGOA beneficiaries will not export at all as the allocation condition 15 is not met for any product.

Bar the case of competitive domestic fabric producers, our model predicts that LDC AGOA beneficiaries such as Lesotho will experience higher growth in export volumes (along both the extensive and intensive margin) to the U.S. than other AGOA beneficiaries. The effect will be particularly pronounced in fabric-intensive apparel products.

Other effects

Other considerations relate to the development of a comparative advantage in the nascent industry. Our model raises a number concerns in relation to this. Firstly, the incentives steer firms to producing products with the lowest value addition conditional on price, rather than up the value-chain. If these products are characterized by low positive growth externalities, then the preference may trap firms into a lower growth path than alternative preferences that incentive greater value addition.

Secondly, our model does not deal with the opportunity cost of resources used in the production of apparel. If labor supply is not infinite, then the growth in the apparel industry will raise wages, which may actually drive out export firms in other sectors where the home country has a comparative advantage. This also holds for other scarce resources such as infrastructure, land and water.

Thirdly, the specialization by firms in fabric-intensive products makes these exporters highly vulnerable to international price volatility (either through exchange rates or international prices), preference erosion through lower MFN tariff rates and the ending of the waiver of the rules of origin. Changes in these variables result in an amplified impact on the effective subsidy provided by the AGOA preferences and the 
MFA quotas. Preference erosion could therefore provide an additional blow that would be seriously underestimated if models fail to capture the contribution of the rule of origin preference.

Finally, the preferences restrict backward linkages by discouraging the addition of value added services from other sectors and inducing exporters to use expensive fabric that is less likely to be produced in poor countries.

\section{Empirical application: Testing Methods and Data}

Our background review identified three distinct trade regimes facing AGOA recipients from the mid-1990s: (a) Quotas under the MFA, (b) AGOA preferences including the third country fabric provision, and (c) the expiration of the MFA. Theory suggests that each of these trade regimes had different impacts on the incentives facing AGOA and non-AGOA countries

In what follows we describe the testing approach we use and then apply this to highly disaggregated U.S. import data. Our specific focus is on changes in the characteristics (value-addition, and fabric intensity) of AGOA apparel exports associated with the MFA and AGOA preferences. We ignore the effects on the value and range of imports as this is already covered by existing empirical research. ${ }^{29}$ The empirical method we use is difference-in-difference estimation applied to price equations. In essence, we identify changes in the fabric-intensity of U.S. apparel

\footnotetext{
${ }^{29}$ We have estimated triple difference-in-difference equations similar to those of Frazer and van Biesebroeck (2010) and do find a surge in apparel imports from lesser-developed beneficiaries relative to other AGOA recipients (and the rest of the world) in response to the third-country fabric provision. The average growth in imports from 2001 through 2004 associated with the fabric-provision is estimated to be up to 282 percent, with stronger effects in products facing high preference margins. We also find that that the expiration of the MFA adversely affected exports from AGOA recipients, but the effect was mitigated for the least developed AGOA countries by the third-party fabric preferences provided under AGOA.
} 
imports from AGOA recipients by analyzing changes in the relationship between apparel import prices and fabric input prices.

We find support for our theoretical predictions. Under the MFA, AGOA recipients are found to be specialized in fabric-intensive clothing products with low value addition relative to quota-constrained (and other) countries. Our estimates suggest, however, that the implementation of AGOA led to no further increases in the overall fabric intensity of these exports. Lesser-developed beneficiaries predominantly expanded the output of the products they were already exporting as a result of their MFA preferences, i.e. growth was primarily along the intensive margin.

However, support for our hypothesis of rising fabric-content in response to the AGOA preferences is found after the expiration of the MFA. China and other previously quota-constrained countries raised the fabric content of their exports after 2005 relative to other emerging economies, as predicted by our theory. More importantly for this study is that we also find a rise in the fabric-content of lesserdeveloped AGOA apparel exports relative to the emerging country control group. AGOA preferences therefore helped insulate recipients in those fabric intensive products that China and other quota constrained countries increasingly entered into after 2005.

\section{Empirical specification of the price equation}

An important limitation of existing empirical studies on the effect of AGOA on import values (Collier \& Venables 2007; Portugal-Perez 2008; Frazer and Van Biesebroeck 2010) is that import value data, even at the HS 10-digit level, is too aggregated to fully capture changes in product characteristics. By only looking at the value or range of HS10-digit products exported by each country, existing studies may miss important changes occurring within each product line. 
Take for example, Figure 6 that plots U.S. import unit values on exporter per capita GDP (both in logarithmic form) for Women's and girls' cotton pullovers (Lesotho's top apparel export) in 2004. The price of imports of this highly disaggregated HS10-digit product ranges from under 10 dollars to over 1000 dollars per square meter equivalent with higher income economies producing the more expensive (higher quality) varieties (as in Hummels and Klenow (2002) and Schott (2004)). The lesser-developed AGOA recipients predominantly situate at the lowprice, low-income per capita end of the spectrum. ${ }^{30}$

[FIGURE 6]

Our particular focus is on product prices. More specifically, we use differencein-difference estimation to exploit the distinct breaks arising from the implementation of AGOA and the ending of the MFA and identify whether prices changes and changes in the fabric-intensity of apparel products are consistent with those predicted by our theory.

Following Feenstra (2004), the U.S domestic price of an imported good $i$ from country $c$ is specified as a function of marginal costs $\left(c^{*}\right)$, the exchange rate $(e)$, import tariffs (tar), aggregate domestic expenditure $(I)$ and the price of substitute goods $(q)$ as follows:

$$
\begin{gathered}
\ln p_{i c t}=\alpha+\beta_{1} \ln c_{i c t}^{*}+\beta_{2} \ln e_{c t}+\beta_{3} \ln q_{i c t} \\
+\beta_{4} \ln \left(1+\operatorname{tar}_{i c t}\right)+\beta_{5} I_{t}+\varepsilon_{t}
\end{gathered} .
$$

\footnotetext{
${ }^{30}$ There are exceptions. Apparel unit values of China, India and Indonesia, who were amongst the top 4 quota restricted countries under the MFA (Brambilla et al. (2010), are higher than predicted. This is consistent theoretical predictions of quality upgrading in response to quota restrictions.
} 
This is an unrestricted version of a price equation that imposes symmetric passthrough of the exchange rate and foreign costs (where $\beta_{1}=\beta_{2}$ ), symmetric passthrough of the tariff and exchange rate (where $\beta_{2}=\beta_{4}$ ) and homogeneity of degree 1 in its arguments $\left(\beta_{1}\left(=\beta_{2}=\beta_{4}\right)+\beta_{3}+\beta_{5}=1\right)$.

We are particularly interested in isolating changes in the fabric content of U.S. apparel imports using this equation. This requires a more precise specification of the influence of fabric costs on unit costs $c^{*}$. To simplify the analysis, we impose a unit cost function derived from a constant return to scale Cobb-Douglas production function:

$$
c_{i c t}^{*}=A_{t} p f_{i t}^{\alpha} p v a_{i c t}^{1-\alpha}
$$

$p f$ is the price of the fabric used in the production of good $i, p v a$ is the value added price (made up labor and capital costs) and $A_{t}$ measures total factor productivity. This specification imposes the restriction that the proportion of expenditure spent by the firm on fabric is constant and is given by $\alpha$. Substituting (18) into (17) gives the following equation:

$$
\begin{aligned}
\ln p_{i t} & =\alpha+\delta_{1} \ln p f_{i t}+\delta_{2} \ln p v a_{i t}+\beta_{2} \ln e_{t}+\beta_{3} \ln q_{i t} \\
& +\beta_{4} \ln \left(1+\operatorname{tar}_{i t}\right)+\beta_{5} I_{t}+\varepsilon_{t}
\end{aligned}
$$

where $\delta_{1}=\beta_{1} \alpha$ and $\delta_{2}=\beta_{1}(1-\alpha)$. Given the assumptions imposed, the fabric content of the clothing product can be calculated as $\delta_{1} /\left(\delta_{1}+\delta_{2}\right)=\beta_{1} \alpha /\left(\beta_{1} \alpha+\beta_{1}(1-\alpha)\right)=\alpha$. Fabric-intensive products would therefore be characterized by large coefficients on the fabric price $\left(\delta_{1}\right)$ relative to the coefficient on the value added price $\left(\delta_{2}\right)$. 
There are two changes in response to the MFA and AGOA that we wish to identify: (i) changes in the price level and (ii) changes in the fabric-intensity of U.S. apparel imports.

To identify changes in the level of import prices from a region in response to a shock, say AGOA recipients after 2001, the above equation is modified to include an interaction between an AGOA dummy variable $(D A g)$ and a dummy variable for the post-AGOA period (D01). The basic price equation in this example is then specified as:

$$
\begin{aligned}
\ln p_{i c t} & =\theta_{1} D 01 \times D A g_{c} \\
& +\delta_{1} \ln p f_{i t}+\delta_{2} \ln p v a_{i c t} \\
& +\beta_{2} \ln e_{c t}+\beta_{3} \ln q_{i c t}+\beta_{4} \ln \left(1+\text { tar }_{i c t}\right) \\
& + \text { cntry/prod }{ }_{c t}+\lambda_{t}+\varepsilon_{i c t}
\end{aligned} .
$$

where $\theta_{1}$ measures the marginal effect of the AGOA preferences (D01) on unit values of U.S. imports from AGOA countries $\left(D A g_{c}\right)$ relative to all other countries in the sample (the control group). Country by product (cntry/prod) fixed effects are included, so the regression uses the within-country by product variation of prices and the other variables over time to estimate the coefficients. ${ }^{31}$ Year fixed effects $\lambda_{t}$ are also included to account for common shocks across all product varieties.

To identify changes in the fabric-intensity associated with the various trade regimes, we focus on changes in the coefficients on the fabric and value added prices. For example, we would expect a shift by AGOA recipients to more fabric intensive varieties within each 10-digit product line to be revealed by a rise in the coefficient on fabric prices and a decline in the coefficient on value added prices.

\footnotetext{
${ }^{31}$ The standard most restrictive difference specification includes a dummy variable for AGOA countries $\left(D A g_{c}\right)$, but in equation 22 these have been replaced with country by product fixed effects (cntry/prod) to allow for country and product level heterogeneity in the base-level of import prices.
} 
We use difference-in-difference estimation to identify changes in the relative fabric-content of apparel imports from AGOA beneficiaries. The specification in the case of AGOA preferences is as follows:

$$
\begin{array}{ll}
r 1: & \ln p_{i c t}=\theta_{1} D 01 \times D A g_{c} \\
r 2: & +\left(\alpha_{1}+\theta_{2} D 01\right) \times D A g_{c} \times \ln p f_{i t} \\
r 3: & +\left(\alpha_{2}+\theta_{3} D 01\right) \times D A g_{c} \times \ln p v a_{i c t} \\
r 4: & +\left(\delta_{1}+\theta_{4} D 01\right) \times \ln p f_{i t} \\
r 5: & +\left(\delta_{2}+\theta_{5} D 01\right) \times \ln p v a_{i c t} \\
r 6: & +\beta_{2} \ln e_{c t}+\beta_{3} \ln q_{i c t}+\beta_{4} \ln \left(1+\text { tar }_{i c t}\right) \\
r 7: & + \text { cntry/ prod } \\
r i c & +\lambda_{t}+\varepsilon_{i c t}
\end{array}
$$

The first row tells us the effect of AGOA on U.S. import unit values of apparel products imported from AGOA recipients. Rows 2 and 3, however, are of most interest to us. The coefficients on the triple interaction terms ( $\theta_{2}$ and $\left.\theta_{3}\right)$ measure the marginal impact of AGOA preferences on the fabric-intensity of U.S. imports from AGOA recipients (first difference) relative to changes in the fabric-intensity of U.S. imports from the control group (second difference). The latter effect is captured by the coefficients $\theta_{4}$ and $\theta_{5}$ in rows 4 and 5 .

For example, support for our hypothesis that AGOA preferences raise the fabric-intensity of imports from recipient countries, would be revealed by a positive coefficient on the AGOA country by post-2001 interaction with the fabric price $\left(\theta_{2}\right)$ in row 2 and a negative coefficient on the AGOA country by post-2001 interaction with the value added price $\left(\theta_{2}\right)$ in row 3. Note that these coefficients reflect the post 2001 impact on fabric-intensity in AGOA countries relative to the post-2001 impact on 
fabric-intensity in the control group which is captured by the coefficients $\theta_{4}$ in row 4 and $\theta_{5}$ in row $5 .^{32}$

Equations 20 and 21 summarize the main approaches used in the following analysis. Further refinements to isolate the marginal effects of the MFA and AGOA preferences on lesser-developed AGOA beneficiary countries will be explained in the relevant empirical sections.

Data

The empirical analysis draws on a panel of time-consistent 10-digit HTS import data for the U.S. from 1996-2008. ${ }^{33}$ The raw data contains approximately 1202 product lines for Clothing (HS61, 62 and various sub-codes of HS 64 \& 65) covering 224 countries.

Unlike the price equations specified above, the dependent variable is the log import price of clothing exclusive of tariffs, insurance and freight costs. This does not affect the estimates, except that the pass-through of tariffs to US domestic prices of imports is calculated as $1-\delta_{7}$. Looking at the independent variables, we use the foreign industry value added deflator (in foreign currency) for $p v a$, the US dollar to foreign currency exchange rate for $e$ and US Producer Prices (at 6-digit NAICS level) (usppi) and competitor clothing unit values (at 10-digit level) (Pcompete) for substitute products $q$. Applied tariff rates are defined at the 4-digit HS level. ${ }^{34}$ In addition to

\footnotetext{
${ }^{32}$ We could also include product by year fixed effects and country by year fixed effects. In this case, only variables defined over product, country and time will be retained.

${ }^{33}$ The HTS classification changed frequently throughout the period as new product lines were introduced and old product lines were aggregated. We use the Pierce and Schott (2009) concordance programme to construct a time-consistent classification for the full period.

${ }^{34}$ We use the average tariff at the HS 4-digit level to avoid erroneous correlations arising from the construction of the variables (tariff rate $=$ duty/import value and price $=$ import value/import quantity). Using the average may also reduce biases associated with the potential endogeneity of product level tariff rates. The trade data are obtained from Peter Schott who constructed the database using US Customs Service data. US producer prices are obtained from the Bureau of Labor Statistics, fabric prices are constructed using UNcomtrade data and the exchange rates are obtained from the World
} 
these variables, real GDP per capita measured in PPP prices is included to capture the impact on prices of general productivity improvements in the economy and relative technological advantage in producing higher-quality goods (Hummels and Klenow 2005). ${ }^{35}$

For fabric prices, we calculate Tornqvist price indices for silk (HS50), wool and fine animal hair (HS51), cotton (HS 52) and man-made fiber and staple (HS 54 \& HS55) using unit values derived from world trade data obtained from UNComtrade. ${ }^{36}$

The calculated fabric indices are presented in Figure $7 .{ }^{37}$ Of interest, is the relatively close association between the average U.S. import unit value of wearing apparel (HS 61 and HS 62) and fabric prices, particularly man-made fabrics.

\section{[FIGURE 7]}

The relevant fabric price (silk, cotton, man-made, wool, or weighted average of these) is allocated to each 10-digit HTS clothing product based on the dominant fabric used in producing the good. ${ }^{38}$ Unfortunately, we are unable to construct

\footnotetext{
Bank World Development Indicator database. Country specific tariff rates at the 4-digit HS level are constructed as the sum of duties collected over value of imports. Competitor clothing prices are calculated as the geometric average price of all other countries (using import values as weights).

${ }^{35}$ Although the industry value added price is the net effect of productivity and nominal factor prices, the real GDP per capita also embodies productivity improvements in the services sector.

36 The following HS codes for synthetic fibres are also included in man-made products: 550110, 550120, 550130, 550190, 550200, 550310, 550320, 550330, 550340, 550390, 550410, 550490, 550610, 550620, 550630, 550690. The average of the fabric prices calculated using world exports and world imports are used.

${ }^{37}$ The fabric prices correspond closely with the dominant agricultural commodity used to produce the fabric. For example, there is a close fit between cotton-based fabric and raw cotton prices, and woolbased fabric and wool prices.

${ }^{38}$ The allocation was done manually on the basis of the product description.
} 
weighted average fabric price indices for apparel products produced using different combinations of fabric types. $^{39}$

We now separately apply the various equations to the AGOA and MFA trade regimes.

\section{African Growth and Opportunity Act}

Our expectation is that AGOA preferences stimulated US imports from beneficiary countries, with relatively high growth in imports of fabric-intensive and low valueadded products. The effects are predicted to be particularly pronounced in LDC recipients eligible to use third country fabric.

Table 5 presents regression results for various specifications of the price equation. The first column presents benchmark estimates of the price relationship over the period 1996-2004 and is used to evaluate the consistency of the price equation with our theoretical priors. Overall, the price model produces results that are consistent with theory and other empirical evidence (See Feenstra 1989.

The dollar price of US clothing imports rise with increases in foreign and US competitor's prices. Import unit values rise with foreign GDP per capita reflecting a positive association between income and quality of exports as explained by Hummels and Klenow (2005). Applied tariffs reduce the fob price of apparel products with a coefficient of -0.60 , which is very close to the effect of an equivalent depreciation of the dollar. ${ }^{40}$ Foreigners therefore absorb 60 percent of tariff increases or depreciation either through lower mark-ups (in case of imperfect competition) and/or reduced marginal costs (from upward sloping supply curve). Further, rising foreign production

\footnotetext{
${ }^{39}$ See Goldberg and Knetter (1997) on how aggregate production cost indices can bias the exchangerate pass-through downwards. The value added deflator is also more aggregated than is desired.

${ }^{40}$ The estimated exchange rate pass-through coefficient of 0.6 falls between Feenstra's (1989) estimates for Trucks (0.63) and Cars (0.71) and more general estimates based on aggregate import data (Marazzi et al. 2005, Gopinath and Rigobon 2008).
} 
costs result in higher U.S. import prices. US import prices are equally affected by increases in foreign fabric costs and value added costs, implying a fabric share coefficient of approximately 50 percent. $^{41}$

\section{[TABLE 5]}

Various diagnostic tests reveal that the aggregate model fails the homogeneity test and the hypothesis of symmetric pass-through of the tariff and exchange rate. However, far fewer instances of rejection are found in the disaggregated HS4-digit level estimates. The disaggregated results and hypotheses tests are presented in Table A1 in the appendix. We are therefore reasonably satisfied with our basic price equation and proceed with our objective of identifying differences in the fabriccontent of AGOA apparel exports.

The second column of results extends the base regression by including interactions between an AGOA dummy (DAg) and fabric costs and value added prices (see rows $9 \& 10$ ). The objective of this estimate is to identify the average fabricintensity of U.S. imports from AGOA beneficiaries throughout the 1996 to 2004 period.

The results indicate that AGOA countries produce relatively fabric-intensive clothing products with low value addition. The coefficient on the fabric price (DAg x $\ln (p f))$ is positive and significant (0.323), while the coefficient on value added prices (DAg $\mathrm{x} \ln (p v a))$ is significant and negative (-0.389). Therefore, U.S unit values of apparel imports from AGOA beneficiaries are far more sensitive to fluctuations in fabric prices than apparel imports from the rest of the world. We infer from this result

\footnotetext{
${ }^{41}$ The coefficients on value added and fabric prices are insignificantly different from each other.
} 
that AGOA beneficiary exports are relatively fabric-intensive. This outcome is consistent with both the effect of the AGOA preferences and the MFA.

To identify the effect of AGOA preferences on beneficiary exports, we use the specification in equation 21 where the time period dummy variable in the interactions refers to the 2001 to 2004 period. ${ }^{42}$ The relevant results are presented in rows 3 \& 4 in column 3 of Table 5. These are the coefficients on the difference-in-difference terms that measure the change in fabric-intensity of U.S. imports from AGOA beneficiaries after 2001 relative to the change in fabric-intensity of imports from the rest of the world. Our expectations are that AGOA preferences raised the fabric-intensity of imports from beneficiary countries.

However, contrary to our theoretical predictions, we find no increase in the fabric-intensity of apparel exports from 2001 to 2004 in response to the AGOA preferences. The coefficients on the interaction terms (D01 x DAg x $\ln (p f))$ in row 3 and (D01 $\times$ DAg $\times \ln (p v a))$ in row 4 are insignificantly different from zero.

One reason may be that the above estimates are an average for both LDC AGOA and other AGOA countries. Our theory suggests that the effect of AGOA preferences on fabric-intensity is particularly pronounced amongst LDC AGOA countries who are eligible for the third country fabric provision. To isolate the marginal impact of the third country fabric provision on fabric-content, we include additional interactions of $\ln (p v a)$ and $\ln (p f)$ on dummy variables for LDC AGOA countries (Dldc) over the full period and over the 2001-04 period. Estimates of this relationship are presented in column 4. The coefficients on the LDC interaction terms

\footnotetext{
${ }^{42}$ Not all countries became eligible to export apparel in 2001. D2001 therefore varies by country and time and equals 1 for all years from the time the country becomes eligible to export apparel products. The dummy variable is set equal to 1 for the initial year if eligibility occurred within the first 6 months of the year.
} 
in rows $2 \& 3$ are interpreted as the marginal impact of AGOA on fabric intensity in LDC special rule countries relative to the rest of AGOA beneficiaries.

We still find no increases in the fabric content of apparel exports by lesserdeveloped AGOA countries relative to other AGOA countries or the rest of the world from 2001 to 2004. None of the marginal effects for LDC Special Rule countries are significantly different from zero.

Overall, the results suggest that the preferences under AGOA had very little impact on the within-product fabric content of apparel exports to the US by recipient countries. AGOA beneficiaries, including lesser-developed Special Rule countries, were already specialized in fabric intensive products prior to receiving AGOA preferences. The impact of AGOA was to make production of these products more attractive and they responded by increasing exports of these products, rather then of new fabric-intensive products. This is consistent with the decomposition of growth analysis in Table 3 which showed that the expansion of exports was overwhelmingly along the intensive margin.

\section{Expiration of MFA}

The ending of the MFA presents an additional policy 'experiment' to test our theory as applied to AGOA beneficiaries. As noted, quotas under the MFA were removed on the $1^{\text {st }}$ January 2005, although some quotas were re-imposed in industrialized countries in response to the rapid growth in imports from China. ${ }^{43}$ In this section, we

\footnotetext{
${ }^{43}$ We do not take into account the re-imposition of quotas on selected Chinese apparel products from late 2005. As shown by Harrigan and Barrow (2010) these contained, but did not reverse the import response to the end of the MFA.
} 
exploit this break to indentify whether import values, import unit values and the fabric-intensity of U.S. apparel imports moved in accordance with our predictions.

Theory predicts that firms in previously quota restricted countries respond to the ending of quotas by downgrading the quality of their apparel exports. In our model, this would be revealed by relatively strong growth in imports of low priced varieties from previously quota restricted countries that include AGOA beneficiaries. Evidence in support of quality downgrading is found by Brambilla et al. (2010) and Harrigan and Barrows (2009).

A second hypothesis derived from our theory, is that, conditional on price, quota restricted countries responded to the ending of the MFA by increasing exports of fabric-intensive apparel products. In this section, we test these two hypotheses focusing on the response by quota restricted countries relative to AGOA beneficiaries.

Preliminary support for the effect of the MFA on product quality is provided in Figure 8 that presents a measure of within-product price differences for selected countries relative to Lesotho. These are calculated by aggregating up the log ratio of export prices relative to Lesotho using Lesotho export values as weights. Higher values reflect the export of more expensive apparel varieties than Lesotho within each product line.

During the MFA period, quota-constrained countries such as China, Bangladesh and India exported varieties within each HS 10 digit line that were up to twice as expensive as those from Lesotho. The expiration of the MFA, however, saw a dramatic decline in the relative price as these countries downgraded the quality of their apparel exports: see the relative price of Chinese apparel that fell from 1.95 times to 90 percent of those from Lesotho in one year. There was a slight rebound 
from 2006 as new quotas on Chinese apparel exports were imposed, but by 2008 relative prices had still fallen by over 55 percentage points from 2004.

[FIGURE 8]

The composition of imports from quota constrained countries also shifted towards the low priced products exported by Lesotho. Figure 9 presents import weighted prices (per square meter equivalent) of apparel imports from each country calculated using the product-level median prices for the entire sample and period and time varying import values by country as weights. Reductions in the average price, reflects across-product shifts in the composition of apparel exports to the U.S. towards lower priced products.

The shift in composition is most noticeable for China, whose apparel exports were initially concentrated in relatively expensive 10-digit apparel products, but then fell in 2002 as quotas imposed under Phase I, II and III of the MFA were eliminated in response to China's entry into the WTO. A further shift towards low priced products occurred in 2005 after the ending of Phase IV of MFA and by 2008 the import weighted median price of Chinese apparel exports was very similar to those of Lesotho.

[FIGURE 9]

The trends in these diagrams provide some support for our hypotheses regarding the effect of quotas on product prices. We now apply the difference-indifference estimation to test for significant changes in the price and fabric-content of apparel exports by AGOA recipients 
Quotas and price levels

The first objective of this section is to estimate if the expiration of the MFA reduced average U.S. import unit values from quota-constrained countries who are predicted to have shifted apparel production towards lower priced products. The equation used to identify these price effects is the difference-in-difference specification of equation 20, except that we replace $D A g$ with a dummy variable Dquotacntry for quota constrained countries and D01 with a post-2005 dummy variable (D05). Table 6 presents the results.

In line with theoretical predictions (and the price trends in Figure 8 and Figure 9), quota constrained countries responded to the end of the MFA by reducing the quality of their apparel exports by shifting towards lower priced varieties and products. The average unit value of U.S. apparel imports from the top 4 most quota constrained countries declined by 31.9 log points relative to other countries after 2005 (see row 1 of column 1 of Table 6) (see also Brambilla et al. (2010) and Harrigan and Barrows (2009)). ${ }^{44}$ This arises from a combination of across-product shifts of imports towards lower price products and within-product shifts towards lower priced varieties. The expiration of the MFA therefore adversely affected the competitiveness of nonquota constrained countries such as Lesotho that produced low priced products in response to the MFA.

\section{[TABLE 6]}

Quotas and fabric-intensity.

\footnotetext{
${ }^{44}$ The decline for the top 30 quota constrained countries is lower at 13.9 percent.
} 
We now test for changes in the fabric-intensity of apparel imports in response to the expiration of the MFA. Our theory predicts a rise in the fabric-content of exports by previously quota constrained countries relative to AGOA beneficiaries and other nonquota constrained exporters.

We commence with the simplest difference-in-difference specification to identify changes in the fabric-intensity of quota-constrained countries in response to the end of the MFA. The specification is similar to that of equation 21, except, as above, a post-2005 dummy variable is used and we also include of various interactions between Dquotacntry and value added and fabric prices covering the pre and post MFA period.

We are interested in two effects: (i) the change in fabric-intensity of exports of the control group (non-quota constrained emerging economies) after January 2005, and (ii) the change in fabric-intensity of exports of the quota-constrained group relative to the control group. The first effect is given by the interactions between the post-MFA dummy (D05) and fabric and value added prices in rows $4 \& 5$ of Table 6 . The second effect is given by the triple interaction between D05, Dquotacntry and fabric and value added prices in rows $6 \& 7$.

The results in rows $4 \& 5$ in column 2 indicate a decline in the fabric-intensity of apparel exports to the U.S from emerging economies after 2005. The coefficient on log fabric prices declines by 10.9 log points, while the coefficient on log value added prices rises by 9.3 log points. This change is consistent with our theory that predicts shifts out of fabric-intensive products by non-quota constrained countries in response to the removal of quotas. 
Our estimates also reveal significant increases in the fabric-intensity of U.S. apparel imports from the most quota-restricted countries. ${ }^{45}$ This is revealed by the significant positive coefficient of 0.217 on the interaction term (D05 x Dquotacntry x $\ln (p f))$ in rows $6 \& 7$ of column 3. Apparel exports from Bangladesh, India, China and Indonesia therefore became more responsive to fabric price fluctuations after 2005 relative to all other emerging economies. We infer from this result that the fabricintensity of apparel exports to the U.S. from these previously quota constrained countries has risen.

The next two estimates focus on identifying the MFA effect on prices and fabric-intensity for AGOA beneficiaries relative to other non-quota constrained emerging economies. We do this by separately including additional triple interactions for the AGOA group (see rows 8 \& 9 column 3) and the LDC AGOA group (see rows $10 \& 11$ column 4$)$.

The estimates produce interesting results. The data suggest that the expiration of the MFA led to a rise in the fabric-intensity of AGOA exports relative to other emerging economies. This is revealed by the rising responsiveness of U.S. import prices from AGOA recipients to changes in fabric prices relative to the control group. If we focus on Lesser-developed beneficiary countries (column 4), we get a similar result.

Clearly AGOA countries have responded differently to other non-quota constrained emerging economies. This is precisely what our theory predicts would happen under AGOA preferences. We found earlier that AGOA resulted in no changes in fabric-intensity of exports by beneficiary countries. Our explanation was

\footnotetext{
45 There is no significant difference from the control group for the top 30 most quota-restricted countries.
} 
that these countries were already specialized in fabric-intensive low value-added apparel products as a result of the incentives introduced by the MFA quotas.

With the end of the MFA, China and other quota-constrained countries moved into the fabric-intensive products they were previously discouraged from exporting under the quotas. This led to increased competition in fabric-intensive products that non-quota constrained countries specialized in under the MFA. The response by these countries was to reduce the fabric-intensity of their apparel exports. AGOA recipients, however, are an exception.

Why? An explanation based on our theory is that AGOA preferences insulated the recipients in the most fabric-intensive products as the effective preferences in these products are the greatest. The effect of AGOA on fabric-intensity is only revealed in our estimates once MFA is removed as prior to this we had an identification problem as both AGOA and MFA encouraged specialization in fabricintensive products.

In sum, the MFA induced AGOA countries to specialize in low value added, high fabric-content apparel products. AGOA preferences and particularly the thirdcountry fabric provision were expected, according to our theory, to compound this specialization in low value-added, fabric-intensive varieties and products. We do not find evidence of significant changes in the fabric-content of apparel exports in response to the AGOA preferences. Rather, the apparel producers in AGOA recipient countries responded by increasing exports of existing products.

The dependence of these exports on the tariff preferences and quota restrictions in competing countries made AGOA recipients and other non-constrained emerging economies very vulnerable to the ending of the MFA. The elimination of quotas (quotas were re-introduced on Chinese exports in later 2005) induced China 
and other previously quota restricted countries to downgrade product quality and increase exports of those products and varieties that AGOA countries were specialized in. However, the effect on fabric-content of AGOA recipient exports was insulated relative to other countries by the AGOA preferences that grant the greatest effective preferences in fabric-intensive products. The AGOA preferences helped mitigate the effects of the expiration of the MFA.

\section{Conclusions}

Lesotho and other Lesser-developed beneficiary countries enjoyed rapid growth in their clothing exports to the US as a result of the third-country fabric provision of AGOA. Although adversely impacted by the expiration of the MFA and the recession in the US, the clothing industries of these least developed African countries have clearly benefited from the provisions. But these economies have not enjoyed the more dynamic upgrading and spill-over benefits that might have been hoped for. Most of the export growth has come in the products that these countries were already producing. Success in the US clothing market has also not translated into success in other clothing markets or in success in exporting other labor-intensive products. The LDBCs have generally remained specialized in a small number of garment categories that are particularly favored by the preferences. These typically embody low-value added in sewing and are relatively intensive in fabric. Although the AGOA program has operated for a decade, it is unlikely that most of the industry in these poor SubSaharan could survive without the special rule.

This experience provides important lessons. Trade preferences do have major advantages. First, they can offer powerful inducements to beneficiary exporters that are financed through foregone tariff revenues by developed countries rather than taxpayers in developing countries. Second, by providing a form of infant industry 
protection in export rather than domestic markets, they ensure that products have to meet the requirements of consumers in advanced economies. And third, since they are externally imposed, they do not give rise to domestic rent-seeking.

The positive response to AGOAs special rule highlights the importance of providing exporters with access to inputs at world prices. Requiring exporters to use expensive inputs can seriously impede their competitiveness. This is clearly seen in the contrast between Lesotho's prowess in the United States where it is allowed to use fabrics that are priced at world prices, with its weak performance in the EU and SACU where it is not. The positive response to AGOA highlights the restrictive nature of other rules of origin that have been imposed on least developed country exports. Allowing LDBCs to use imported fabrics provided powerful effective subsidies for clothing exports. This served to compensate producers in poor countries for the lower productivity of domestic workers and other institutional and infrastructural deficiencies.

The fact that the program has operated smoothly without problems relating to trade deflection demonstrates the scope for improving the restrictive rules that continue to limit the benefits to poor countries from programs such as the EBA program of the European Union. Such improvements would create more realistic possibilities that the least developed countries could participation in global production chains. It would be particularly welcome given the problems faced by these countries as a result of the expiration of the MFA.

In the Doha Round, it is recognized that lower MFN tariffs will result in preference erosion. But typically studies have suggested that the effects would not be 
large. ${ }^{46}$ However, if the models that are used to estimate the impact of erosion fail to take the third-country fabric provision into account they could seriously underestimated the impact on the effective protection provided to the Lesserdeveloped AGOA recipients.

The experience also shows, however, that trade preferences are not a panacea. The outcomes associated with the special rule conform to those suggested by theory. The special rule distorts decisions on value-addition and fabric use in opposite directions, both of which are undesirable. On the one hand, the incentives are most powerful in lower quality products that require less value-addition. This may limit the dynamic benefits that are hoped for from these preferences by discouraging skills development and other forms of quality upgrading. On the other hand it encourages the use of more expensive fabrics. This makes it less likely that there will be backward linkages into domestic textile industries that are still at rudimentary stages of development.

Preferences are thus an opportunity but not a substitute for more comprehensive industrial strategies that involve complementary domestic policies to improve private and governmental capabilities. This does not mean that these preferences are unimportant, but suggests they are unlikely to be sufficient. In addition problems arise when most of the entrepreneurs taking advantage of the preferences are foreign, with many other crucial parts of the value chain being provided thousands of miles away.

The experience analyzed in this paper is a case study of the links between trade and growth -- a topic that has been the subject of considerable empirical

\footnotetext{
${ }^{46}$ For estimates of the impact of preference erosion see IMF (2003), Olarreaga and Özden (2005), Hoekman and Prowse ( 2005) and Grynberg and Silva (2004).
} 
investigation. This example highlights the obvious, but often ignored consideration, that both trade and growth are quintessentially endogenous variables rather than policy instruments and suggests that the reasons for trade are likely to be important in the impact on growth. Even if on average trade and growth are associated, and even if on average trade may cause growth, the widely used proposition that trade leads to growth should not be used as an unconditional forecast. The precise reasons for trade and the other domestic conditions and policies that are associated with it, are likely to play key roles in the growth impact. In the case of Lesotho and other AGOA countries utilizing preferences may lead to more trade but are not a substitute for the more difficult challenges of developing more comprehensive development strategies. In sum, the slogan of "trade not aid" can be misleading. Trade preferences may be help create the conditions for growth, but they are not sufficient 


\section{References}

Alchian, Armen A., and William R. Allen (1964). University Economics. Belmont, Calif.: Wadsworth.

Bennet, Mark (2006). "Lesotho’s Export Textiles \& Garment Industry.” In Herbert Jauch and Rudolf Traub-Merz (Eds.) The Future of the Textile and Clothing Industry in Sub-Saharan Africa, Bonn: Friedrich-Ebert-Stiftung.

Brambilla, Irene, Amit K. Khandelwal, Peter K. Schott (2010). “China's Experience under the Multi-Fiber Arrangement (MFA) and the Agreement on Textiles and Clothing (ATC).” In Robert C. Feenstra and Shang-Jin Wei (editors) China's Growing Role in World Trade, National Bureau of Economic Research.

Brenton Paul and Takako Ikezuki (2004). “The Initial and Potential Impact of Preferential Access to the U.S. Market under the African Growth and Opportunity act,” World Bank Policy Research Working Paper 3262, April 2004.

Collier, Paul and Anthony J. Venables (2007). "Rethinking Trade Preferences: How Africa Can Diversify its Exports,” The World Economy, Vol. 30, No. 8, pp. 13261345.

Collier, Paul and Jan Willem Gunning (1999). "Explaining African Economic Performance,” Journal of Economic Literature, March 1999 37, pp 64 - 111.

Dixit, Avinash K., and Victor Norman (1980). Theory of International Trade. Cambridge Economic Handbooks, Cambridge University Press.

Dixit, Avinash. K., and Joseph. E. Stiglitz (1977). "Monopolistic Competition and Optimum Product Diversity,” American Economic Review, Vol. 67, No. 3, pp. 297-308.

Dornbusch, Rudiger, Stanley Fischer and Paul A. Samuelson. (1977). "Comparative advantage, trade and payments in a Ricardian Model with a continuum of goods," American Economic Review, Vol. 65, pp 297-308.

Falvey, Rodney E (1979). “The Composition of Trade within Import-restricted Product Categories,” The Journal of Political Economy, Vol. 87, No. 5, Part 1 (Oct., 1979), pp. 1105-1114.

Feenstra, Robert C. (1988). "Quality Change under Trade Restraints in Japanese Autos,” Quarterly Journal of Economics, Vol. 103, No. 1 (Feb., 1988), pp. 131146.

Feenstra, Robert C. (2004). Advanced international trade: theory and evidence, Princeton University Press.

FIAS (2006). “The Competitiveness of Regional and Vertical Integration of Lesotho's Garment Industry” IFC and World Bank: Washington DC 2006.

Frazer, Garth and Johannes Van Biesbroeck (2010). "Trade Growth Under the African Growth and Opportunity Act," Review of Economics and Statistics, Vol. 92, No. 1, pp. 128-144.

Gereffi, G. (1999). "International trade and industrial upgrading in the clothing commodity chain,” Journal of International Economics, Vol. 48, pp. 37-70.

Gibbon, Peter (2003). "The African Growth and Opportunity Act and the Global Commodity Chain for Clothing,” World Development Vol. 31, No. 1, pp. 18091827. 
Goldberg, Pinelopi .K. and Michael M. Knetter (1997). "Goods prices and exchange rates: what have we learned?” Journal of Economic Literature XXXV, pp. 12431272.

Gopinath, Gita, and Roberto Rigobon (2008). "Sticky Borders," The Quarterly Journal of Economics, Vol. 123, No. 2, Pages 531-575.

Grynberg, Roman, and Sacha Silva (2004). Preference-Dependent Economies and Multilateral Liberalization: Impacts and Options. London: Commonwealth Secretariat.

Harrigan, James and Geoffrey Barrows (2009). "Testing the Theory of Trade Policy: Evidence from the Abrupt End of the Multifiber Arrangement," The Review of Economics and Statistics, MIT Press, Vol. 91, No. 2, pp. 282-294.

Hausmann, Ricardo, Jason Hwang and Dani Rodrik (2007). "What you export matters,” Journal of Economic Growth, Springer, Vol. 12, No. 1, pp. 1-25.

Hoekman, Bernard, and Susan Prowse (2005). "Policy Response to Preference Erosion: From Trade as Aid to Aid for Trade". Paper Presented at the international symposium "Preference Erosion: Impacts and Policy Responses”, Geneva, June 13-14.

Hummels, David and Alexandre Skiba (2004). "Shipping the Good Apples out? An Empirical Confirmation of the Alchian-Allen Conjecture," The Journal of Political Economy, Vol. 112, No. 6 (Dec., 2004), pp. 1384-1402

Hummels, David and Peter J. Klenow (2005). “The Variety and Quality of a Nation's Exports,” The American Economic Review, Vol. 95, No. 3 (Jun., 2005), pp. 704723.

Hwang, Jason Jaemin (2007) Patterns of Specialization and Economic Growth, Phd Thesis, Harvard University.

IMF (2003). "Financing Losses from Preference Erosion, Note on Issues raised by Developing Countries in the Doha Round." Communication to the WTO from the International Monetary Fund, WT/TF/COH/14 February. Prepared by Arvind Subramanian.

Krishna, Kala (1987). “Tariffs versus quotas with endogenous quality,” Journal of International Economics, Elsevier, Vol. 23(1-2), pp. 97-112.

Krugman, Paul R. (1979). "Increasing returns, monopolistic competition, and international trade,” Journal of International Economics, Elsevier, Vol. 9, No. 4, pp. 469-479.

Lall, Sanjaya (2005). "FDI, AGOA, and Manufactured Exports From a Land-Locked Least Developed African Economy: Lesotho,” Journal of Development Studies, August 2005, Vol. 41, No. 6, pp. 998-1022.

Maloney, Christopher (2006). “All Dressed Up with No Place to Go? Lesotho’s Rollercoaster Experience with Apparel,” Harvard Kennedy School MPA/ID Second Year Policy Analysis

Marazzi, M., N. Sheets, R. Vigfusson, J. Faust, J. Gagnon, J. Marquez, R. Martin, T. Reeve, and J. Rogers, "Exchange Rate Pass-Through to U.S. Import Prices: Some New Evidence,” International Finance Discussion Papers, No. 833, 2005.

Mattoo, Aadditya; Devesh Roy, and Arvind Subramanian (2003). “The Africa Growth and Opportunity Act and its Rules of Origin: Generosity Undermined?” World Economy, Vol. 26, No. 6, pp. 829-851. 
Morris, Mike (2006). 'China's dominance of global clothing and textiles: is preferential trade access an answer for sub-Saharan Africa?,” IDS Bulletin, Vol. 37, No. 1, pp. 89-97.

Morris, Mike and Leanne Sedowski (2006). "Report on Government Responses to New post-MFA realities in Lesotho,” Report for Institute of Global Dialogue.

Ng, Francis, and Alexander Yeats. 1996. “Open economies work better: Did Africa’s protectionist policies cause its marginalisation in world trade?” World Bank Policy Research Working paper No. 1636. World Bank, Washington DC.

Nouve, Kofi (2005). "Estimating the Effects of AGOA on African Exports Using a Dynamic Panel Analysis” World Bank Working Paper July 2005.

Olarreaga, Marcelo and Çaglar Özden (2005).“AGOA and Apparel: Who Captures the Tariff Rent in the Presence of Preferential Market Access?” World Economy, Vol. 28, No.1, pp. 63-77.

Pierce, Justin R. and Peter K. Schott (2009). "Concording U.S. Harmonized System Categories over Time,” Center for Economic Studies (CES) Working Paper 09-11.

Portugal-Perez, Albert (2008). "The costs of rules of origin in Apparel: African preferential exports to the United States and the European Union," UNCTAD Policy Issues in International Trade and commodities Study Series No. 39, UNCTAD.

Rolfe, Robert J. and Douglas P. Woodward (2005). “African Apparel Exports, AGOA and the Trade Preference Illusion,” Global Economy Journal, Berkley Electronic Press, Vol. 5, Issue 3.

Romalis, John (2007). “Market Access, Openness and Growth” National Bureau of Economic Research Working Paper 13048.

Salm, Andrew, William J. Grant, Thuso J. Green, John R. Haycock and John Raimondo (2002). "Lesotho Garment Industry Subsector Study” Report for the Government of Lesotho,” study funded by the Department for International Development.

Sandrey Ron, David Maleleka Adelaide Matlanyane, and Dirk Ernst van Seventer (2005). “Lesotho: Potential Export Diversification Study”, (Mimeo)

Schott, Peter K. (2004). “Across-product Versus Within-product Specialization in International Trade,” The Quarterly Journal of Economics, Vol. 119, No. 2, pp. 646-677.

Seidman, Gay W. (2009). "Labouring under an Illusion? Lesotho's 'sweat-free' label,” Third World Quarterly, Vol. 30, No. 3, pp. 581 - 598.

Seyoum, Belay (2007). "Export Performance of developing countries under the Africa Growth and Opportunity Act,” Journal of Economic Studies, Emerald Group Publishing, Vol. 34, No. 6, pp. 515 - 533.

Wang, Zhen Kun, and Alan Winters (1998). “Africa’s Role in Multilateral Trade Negotiations: Past and Future,” Journal of African Economies Vol. 7, pp. 1-33.

Wood, Adrian. and Jörg Mayer (2001). “Africa’s Export Structure in a Comparative Perspective,” Cambridge Journal of Economics, Vol. 5, No. 3, pp. 369-394. 
TABLES

Table 1: Summary of Apparel Rules of Origin under AGOA

\begin{tabular}{|l|l|}
\hline Description of the rules of origin requirements & Conditions of Access \\
\hline 1. Apparel made from U.S. yarns or fabric & Unrestricted \\
\hline $\begin{array}{l}\text { 2. Apparel assembled from regional fabric from U.S. or } \\
\text { African yarn }\end{array}$ & $\begin{array}{l}\text { Subject to tariff rate quota cap (currently } \\
6.43675 \text { percent to 2015) }\end{array}$ \\
\hline $\begin{array}{l}\text { 3. Apparel assembled in a Lesser Developed Country } \\
\text { using foreign fabric or yarn }\end{array}$ & $\begin{array}{l}\text { Unrestricted for four years, but extended to } \\
2012 \text { (cap of 3.5 percent of US imports) }\end{array}$ \\
\hline 4. Certain cashmere and merino wool sweaters; & Unrestricted for selected products \\
\hline $\begin{array}{l}\text { 5. Apparel made of yarns and fabrics not produced in } \\
\text { commercial quantities in the US }\end{array}$ & Unrestricted \\
\hline $\begin{array}{l}\text { 6. Eligible handloomed, handmade, or folklore articles } \\
\text { and ethnic printed fabrics; and }\end{array}$ & $\begin{array}{l}\text { Unrestricted for selected products from Dec } \\
2006 \text { under AGOA IV }\end{array}$ \\
\hline
\end{tabular}

Note: Unrestricted implies duty-free and quota-free treatment.

Table 2: Products traded (out of approx 1,500 possible products), sorted by 2004

\begin{tabular}{|c|c|c|c|c|c|}
\hline Eligibility & Country & 1996 & 2000 & 2004 & 2008 \\
\hline Apparel & Mauritius & 165 & 139 & 135 & 139 \\
\hline eligible & South Africa & 136 & 267 & 318 & 177 \\
\hline \multirow{24}{*}{ 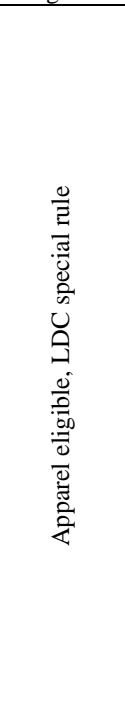 } & Benin & 2 & 2 & 4 & 0 \\
\hline & Botswana & 14 & 24 & 57 & 18 \\
\hline & Burkina & 8 & 9 & 9 & 4 \\
\hline & Cameroon & 10 & 7 & 14 & 18 \\
\hline & Cape Verde & 2 & 4 & 14 & 5 \\
\hline & Chad & 0 & 0 & 1 & 0 \\
\hline & Ethiopia & 9 & 4 & 41 & 79 \\
\hline & Ghana & 38 & 52 & 63 & 48 \\
\hline & Kenya & 55 & 45 & 155 & 117 \\
\hline & Lesotho & 41 & 60 & 118 & 84 \\
\hline & Madagascar & 38 & 175 & 236 & 259 \\
\hline & Malawi & 2 & 22 & 45 & 25 \\
\hline & Mali & 10 & 10 & 12 & 11 \\
\hline & Mozambique & 3 & 0 & 7 & 0 \\
\hline & Namibia & 0 & 1 & 40 & 2 \\
\hline & Niger & 4 & 4 & 7 & 5 \\
\hline & Nigeria & 61 & 47 & 39 & 33 \\
\hline & Rwanda & 0 & 0 & 2 & 5 \\
\hline & Senegal & 31 & 20 & 10 & 16 \\
\hline & Sierra Leone & 2 & 28 & 45 & 54 \\
\hline & Swaziland & 21 & 47 & 139 & 86 \\
\hline & Tanzania & 4 & 6 & 24 & 16 \\
\hline & Uganda & 0 & 0 & 9 & 4 \\
\hline & Zambia & 1 & 1 & 4 & 4 \\
\hline \multirow{16}{*}{ 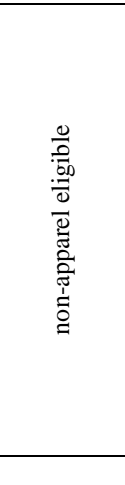 } & Angola & 0 & 0 & 0 & 0 \\
\hline & Burundi & 1 & 1 & 0 & 0 \\
\hline & Comoros & 1 & 0 & 1 & 0 \\
\hline & Congo (Brazzaville) & 0 & 0 & 3 & 0 \\
\hline & Congo (Kinshasa) & 3 & 4 & 1 & 3 \\
\hline & Djibouti & 0 & 0 & 0 & 0 \\
\hline & Gabon & 1 & 1 & 3 & 0 \\
\hline & Gambia & 6 & 11 & 7 & 9 \\
\hline & Guinea & 5 & 12 & 13 & 12 \\
\hline & Guinea-Bissau & 0 & 0 & 0 & 3 \\
\hline & Liberia & 2 & 3 & 2 & 3 \\
\hline & Sao Tome and & & & & \\
\hline & Principe & 1 & 1 & 0 & 0 \\
\hline & Seychelles & 0 & 2 & 3 & 6 \\
\hline & Togo & 13 & 4 & 3 & 4 \\
\hline & All AGOA countries & 323 & 439 & 537 & 465 \\
\hline $\begin{array}{l}\text { Possible } \\
\text { products }\end{array}$ & & 1,548 & 1,533 & 1,525 & 1,515 \\
\hline
\end{tabular}

Notes: We use the Pierce and Schott (2009) concordance programme to construct a HS 10-digit timeconsistent classification for the full period. 
Table 3: Decomposition of growth in US apparel imports: Extensive and Intensive growth

\begin{tabular}{|c|c|c|c|c|c|c|c|c|}
\hline & & $\begin{array}{l}\text { Contributio } \\
\text { n Intensive } \\
\text { growth }\end{array}$ & $\begin{array}{l}\text { Contributi } \\
\text { on } \\
\text { Extensive } \\
\text { growth }\end{array}$ & $\begin{array}{l}\begin{array}{l}\text { Average } \\
\text { annual }\end{array} \\
\text { Growth } \\
\text { (US\$) }\end{array}$ & $\begin{array}{l}\text { Contributio } \\
\mathrm{n} \\
\text { growth } \\
\end{array}$ & $\begin{array}{l}\text { Contributi } \\
\text { on } \\
\text { Extensive } \\
\text { growth }\end{array}$ & $\begin{array}{l}\text { Average } \\
\text { annual } \\
\text { Growth } \\
\text { (US\$) }\end{array}$ & \begin{tabular}{|l} 
Cumulative \\
imports \\
2004 \\
\end{tabular} \\
\hline \multirow{25}{*}{ 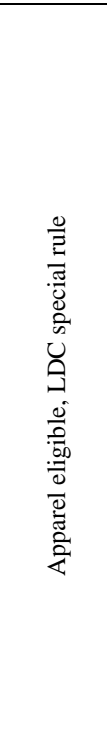 } & & \multicolumn{3}{|c|}{$2000-04$} & \multicolumn{4}{|c|}{$2004-08$} \\
\hline & Benin & 0.00 & 1.00 & 0.33 & 0.00 & 1.00 & -1.00 & 0.00 \\
\hline & Botswana & 0.24 & 0.76 & 0.27 & -1.56 & 2.56 & -0.06 & 0.01 \\
\hline & Burkina Faso & -0.02 & 1.02 & 0.28 & 0.00 & 1.00 & -0.49 & 0.01 \\
\hline & Cameroon & 0.00 & 1.00 & 0.22 & -0.27 & 1.27 & 0.21 & 0.01 \\
\hline & Cape Verde & 0.33 & 0.67 & 0.36 & 0.00 & 1.00 & -0.73 & 0.01 \\
\hline & Chad & 0.00 & 1.00 & & 0.00 & 1.00 & -1.00 & 0.01 \\
\hline & Ethiopia & 0.00 & 1.00 & 4.00 & 0.52 & 0.48 & 0.30 & 0.02 \\
\hline & Ghana & 0.02 & 0.98 & 1.18 & 0.95 & 0.05 & -0.41 & 0.02 \\
\hline & Kenya & 0.68 & 0.32 & 0.59 & 0.81 & 0.19 & -0.03 & 0.18 \\
\hline & Lesotho & 0.92 & 0.08 & 0.34 & 0.87 & 0.13 & -0.07 & 0.44 \\
\hline & Madagascar & 0.78 & 0.22 & 0.31 & 0.91 & 0.09 & -0.04 & 0.62 \\
\hline & Malawi & 0.51 & 0.49 & 0.38 & 0.32 & 0.68 & -0.17 & 0.64 \\
\hline & Mali & 1.19 & -0.19 & -0.17 & 0.90 & 0.10 & 0.37 & 0.64 \\
\hline & Mozambique & 0.00 & 1.00 & & 0.00 & 1.00 & -1.00 & 0.64 \\
\hline & Namibia & 0.00 & 1.00 & 3.69 & 0.07 & 0.93 & -0.94 & 0.68 \\
\hline & Niger & -0.82 & 1.82 & 0.11 & 0.44 & 0.56 & 0.18 & 0.68 \\
\hline & Nigeria & 1.90 & -0.90 & -0.07 & -0.10 & 1.10 & -0.08 & 0.68 \\
\hline & Rwanda & 0.00 & 1.00 & & 0.00 & 1.00 & 0.92 & 0.68 \\
\hline & Senegal & 0.73 & 0.27 & -0.30 & 0.65 & 0.35 & 0.16 & 0.68 \\
\hline & Sierra Leone & 0.40 & 0.60 & 0.59 & 0.19 & 0.81 & -0.39 & 0.68 \\
\hline & Swaziland & 0.57 & 0.43 & 0.54 & 0.63 & 0.37 & -0.09 & 0.79 \\
\hline & Tanzania & 0.24 & 0.76 & 1.80 & -0.25 & 1.25 & -0.12 & 0.79 \\
\hline & Uganda & 0.00 & 1.00 & & -0.04 & 1.04 & -0.44 & 0.79 \\
\hline & Zambia & 0.00 & 1.00 & -0.42 & 0.00 & 1.00 & -0.52 & 0.79 \\
\hline \multirow{2}{*}{$\begin{array}{l}\text { Apparel } \\
\text { eligible }\end{array}$} & Mauritius & 0.67 & 0.33 & -0.02 & 0.94 & 0.06 & -0.18 & 0.92 \\
\hline & South Africa & -17.67 & 18.67 & 0.00 & 0.80 & 0.20 & -0.40 & 1.00 \\
\hline \multirow{12}{*}{ 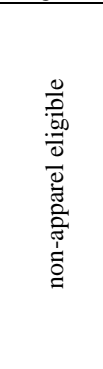 } & Burundi & 0.00 & 1.00 & -1.00 & & & & 1.00 \\
\hline & Comoros & 0.00 & 1.00 & & 0.00 & 1.00 & -1.00 & 1.00 \\
\hline & Congo (DROC) & 0.00 & 1.00 & -0.19 & 0.00 & 1.00 & 1.45 & 1.00 \\
\hline & Congo (ROC) & 0.00 & 1.00 & & 0.00 & 1.00 & -1.00 & 1.00 \\
\hline & Gabon & 0.00 & 1.00 & 2.56 & 0.00 & 1.00 & -1.00 & 1.00 \\
\hline & Gambia & -0.32 & 1.32 & -0.14 & 0.90 & 0.10 & 0.32 & 1.00 \\
\hline & Guinea & -0.02 & 1.02 & -0.42 & 1.01 & -0.01 & 0.11 & 1.00 \\
\hline & Guinea-Bissau & & & & 0.00 & 1.00 & & 1.00 \\
\hline & Liberia & 0.00 & 1.00 & -0.34 & 0.00 & 1.00 & 0.12 & 1.00 \\
\hline & Sao Tome \& Principe & 0.00 & 1.00 & -1.00 & & & & 1.00 \\
\hline & Seychelles & 0.95 & 0.05 & -0.64 & 0.00 & 1.00 & 0.97 & 1.00 \\
\hline & Togo & 0.00 & 1.00 & -0.18 & 0.00 & 1.00 & 0.47 & 1.00 \\
\hline \multicolumn{2}{|c|}{ All AGOA } & 0.68 & 0.32 & 0.25 & 0.70 & 0.30 & -0.10 & \\
\hline \multicolumn{2}{|c|}{ LDC special rule eligible } & 0.69 & 0.31 & 0.42 & 0.58 & 0.42 & -0.07 & \\
\hline \multicolumn{2}{|c|}{ Other apparel eligible } & 1.05 & -0.05 & -0.01 & 0.87 & 0.13 & -0.25 & \\
\hline \multicolumn{2}{|c|}{ Other AGOA } & -2.03 & 3.03 & 0.04 & -0.18 & 1.18 & -0.21 & \\
\hline
\end{tabular}

Note: Mauritius is treated as not eligible to export under LDC special rule, despite being granted temporary LDC status from October 2004-September 2005 under the Miscellaneous Tariff Bill of 2004 (known as AGOA III). 
Table 4: Price (US\$ per dozen) of top 15 Lesotho products in terms of export value, ranked largest to smallest, 2004

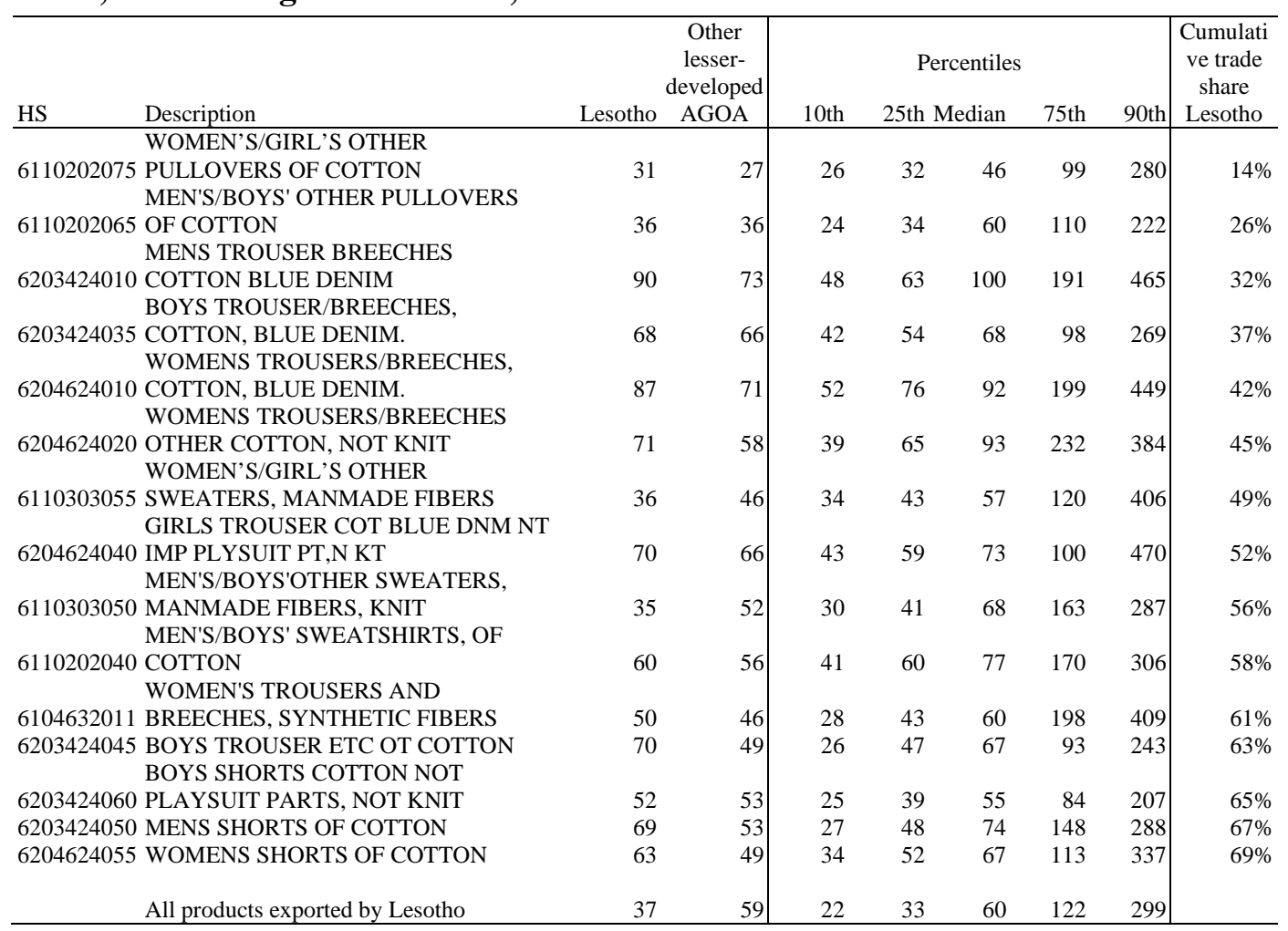

Notes: The mean price for Other AGOA is the exponent of the mean log price. 
Table 5: Marginal impact of AGOA preferences on fabric-intensity in beneficiary countries

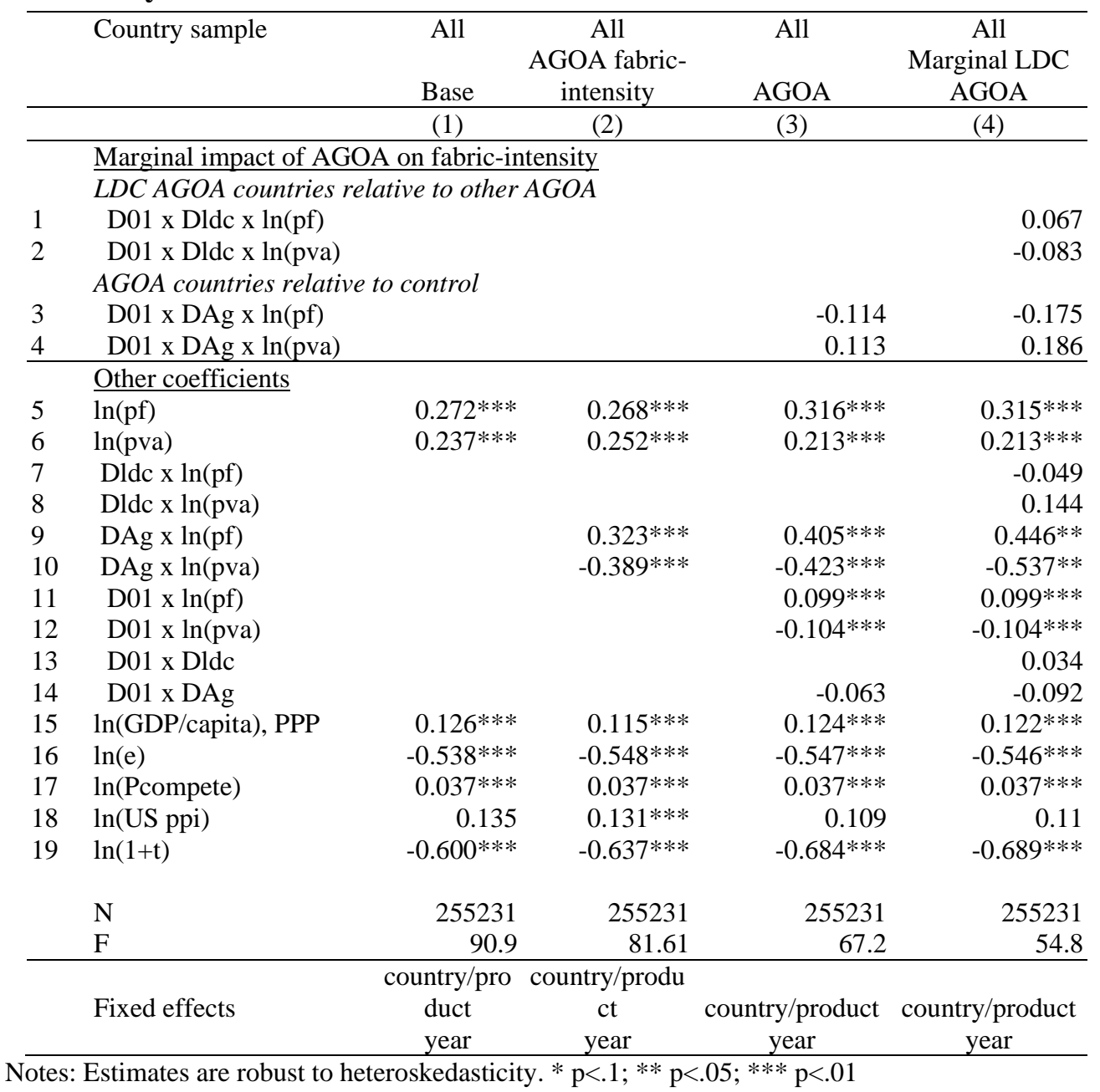


Table 6: Marginal impact of the ending of the MFA on import unit values and fabric-intensity in Apparel eligible AGOA beneficiaries

\begin{tabular}{|c|c|c|c|c|c|}
\hline & Country sample & $\begin{array}{l}\text { Base price } \\
\text { Emerging } \\
\quad(1)\end{array}$ & $\begin{array}{l}\text { Base fabric } \\
\text { Emerging } \\
(2)\end{array}$ & $\begin{array}{l}\text { AGOA } \\
\text { Emerging } \\
(3)\end{array}$ & $\begin{array}{l}\text { LDC Agoa } \\
\text { Emerging } \\
(4)\end{array}$ \\
\hline & $\begin{array}{l}\text { Impact of ending of MFA on U.S. import pri } \\
\text { Quota constrained relative to control (D05 }\end{array}$ & ces & & & \\
\hline $\begin{array}{l}1 \\
2\end{array}$ & $\begin{array}{l}\text { x Dquotacntry) } \\
\text { AGOA relative to control (D05 x DAg) } \\
\text { LDC AGOA relative to other AGOA (D05 }\end{array}$ & $-0.319 * * *$ & $-0.580 * * *$ & $\begin{array}{l}-0.567 * * * \\
0.422 * * *\end{array}$ & $-0.573 * * *$ \\
\hline 3 & $\begin{array}{l}\mathrm{x} \text { Dldc }) \\
\text { Marginal impact of ending of MFA on fabri } \\
\text { Control group }\end{array}$ & -intensity & & & 0.111 \\
\hline $\begin{array}{l}4 \\
5\end{array}$ & $\begin{array}{l}D 05 \times \ln (p f) \\
\text { D05 } x \ln (p v a) \\
\text { Quota-constrained group relative to control }\end{array}$ & rroup & $\begin{array}{l}-0.107 * * * \\
0.093 * * *\end{array}$ & $\begin{array}{c}-0.087 * * * \\
0.073^{* *}\end{array}$ & $\begin{array}{l}-0.098 * * * \\
0.084 * * *\end{array}$ \\
\hline $\begin{array}{l}6 \\
7\end{array}$ & $\begin{array}{l}\text { D05 x Dquotacntry x } \ln (p f) \\
\text { D05 x Dquotacntry x } \ln (p v a) \\
\text { AGOA countries relative to control group }\end{array}$ & & $\begin{array}{c}0.217 * * * \\
-0.112\end{array}$ & $\begin{array}{l}0.219 * * * \\
-0.112\end{array}$ & $\begin{array}{c}0.209 * * * \\
-0.104\end{array}$ \\
\hline $\begin{array}{l}8 \\
9\end{array}$ & $\begin{array}{l}D 05 \times D A g \times \ln (p f) \\
D 05 \times D A g \times \ln (p v a) \\
\text { LDC AGOA countries relative to other AGC }\end{array}$ & & & $\begin{array}{l}0.294^{* * *} \\
-0.317 * * *\end{array}$ & \\
\hline $\begin{array}{l}10 \\
11\end{array}$ & $\begin{array}{l}D 05 \times \text { Dldc } \times \ln (p f) \\
\text { D05 x Dldc x } \ln (p v a)\end{array}$ & & & & $\begin{array}{c}0.273 * * \\
-0.260 * * \\
\end{array}$ \\
\hline & Other variables & & & & \\
\hline 12 & $\ln (p f)$ & $0.619 * * *$ & $0.443^{* * *}$ & $0.468 * * *$ & $0.430 * * *$ \\
\hline 13 & $\ln (p v a)$ & $0.381^{* * *}$ & $0.288^{* * *}$ & $0.332^{* * *}$ & $0.320 * * *$ \\
\hline 14 & Dquotacntry x $\ln (p f)$ & & $0.599 * * *$ & $0.631^{* * *}$ & $0.628 * * *$ \\
\hline 15 & Dquotacntry $x \ln (p v a)$ & & $-0.898 * * *$ & $-0.938 * * *$ & $-0.917 * * *$ \\
\hline 16 & $D A g \times \ln (p f)$ & & & $0.432 * * *$ & \\
\hline 17 & $D A g \times \ln (p v a)$ & & & $-0.324 * * *$ & \\
\hline 18 & Dldc $\times \ln (p f)$ & & & & $0.373^{* * *}$ \\
\hline 19 & Dldc $\mathrm{x} \ln (p v a)$ & & & & $-0.297 * * *$ \\
\hline 20 & $\ln (G D P /$ capita $), \mathrm{PPP}$ & $0.152 * * *$ & $0.578 * * *$ & $0.580 * * *$ & $0.534 * * *$ \\
\hline 21 & $\ln (e)$ & $-1.141 * * *$ & $-0.886 * * *$ & $-0.980 * * *$ & $-0.918 * * *$ \\
\hline 22 & $\ln ($ Pcompete $)$ & $0.028 * *$ & $0.038 * * *$ & $0.037 * * *$ & $0.038 * * *$ \\
\hline 23 & $\ln (U S$ ppi) & $0.216^{*}$ & $0.230 *$ & $0.234^{*}$ & $0.220 *$ \\
\hline 24 & $\ln (1+t)$ & $-0.637 * * *$ & $-0.681 * * *$ & $-0.661^{* * *}$ & $-0.701 * * *$ \\
\hline & $\begin{array}{l}\mathrm{N} \\
\mathrm{F}\end{array}$ & $\begin{array}{c}102208 \\
168\end{array}$ & $\begin{array}{c}102208 \\
131\end{array}$ & $\begin{array}{c}102208 \\
108\end{array}$ & $\begin{array}{c}102208 \\
106\end{array}$ \\
\hline & Fixed effects & $\begin{array}{l}\text { country/prod } \\
\text { uct } \\
\text { year }\end{array}$ & $\begin{array}{l}\text { country/prod } \\
\text { uct } \\
\text { year }\end{array}$ & $\begin{array}{l}\text { country/prod } \\
\text { uct } \\
\text { year }\end{array}$ & $\begin{array}{l}\text { country/prod } \\
\text { uct } \\
\text { year }\end{array}$ \\
\hline
\end{tabular}

Notes: Estimates are robust to heteroskedasticity. ${ }^{*} \mathrm{p}<.1{ }^{* *} \mathrm{p}<.05 ;{ }^{* * *} \mathrm{p}<.01$ 


\section{FIGURES}

Figure 1: US apparel imports from AGOA countries according to import program

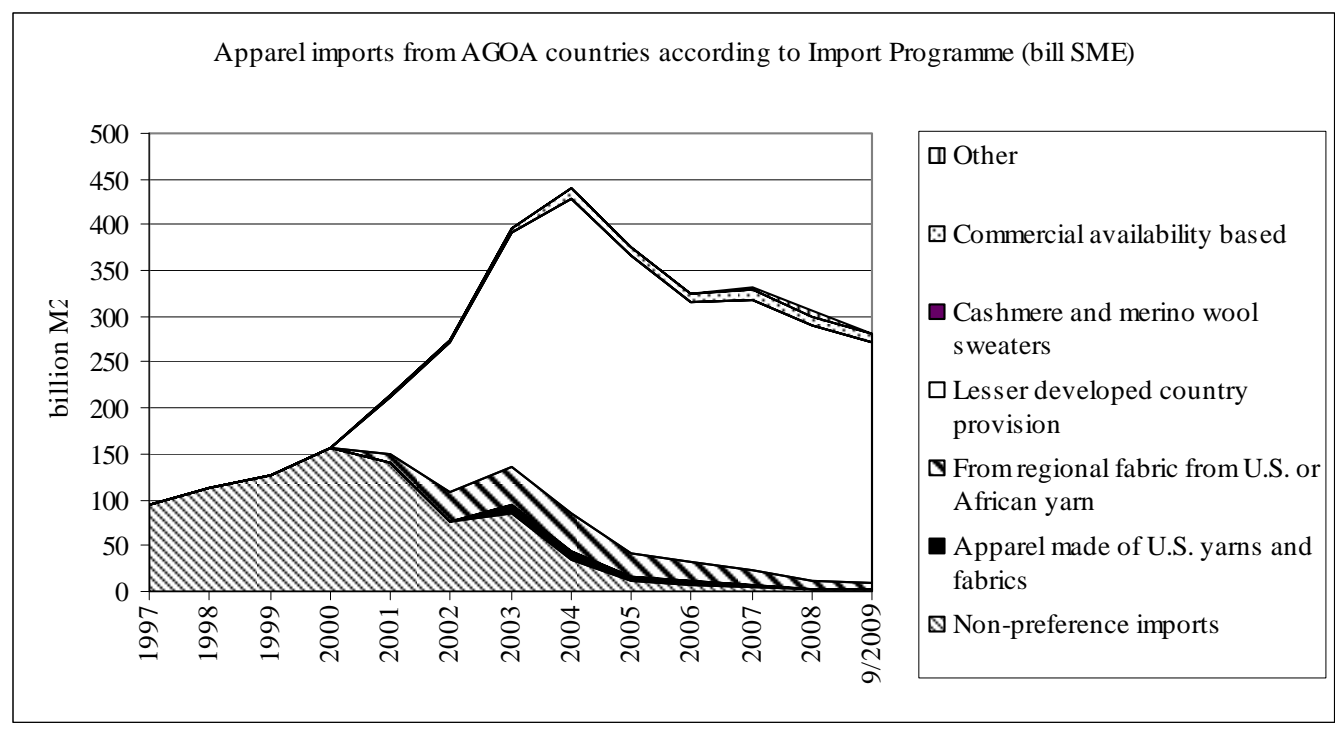

Source: USITC

Figure 2: US imports from AGOA countries

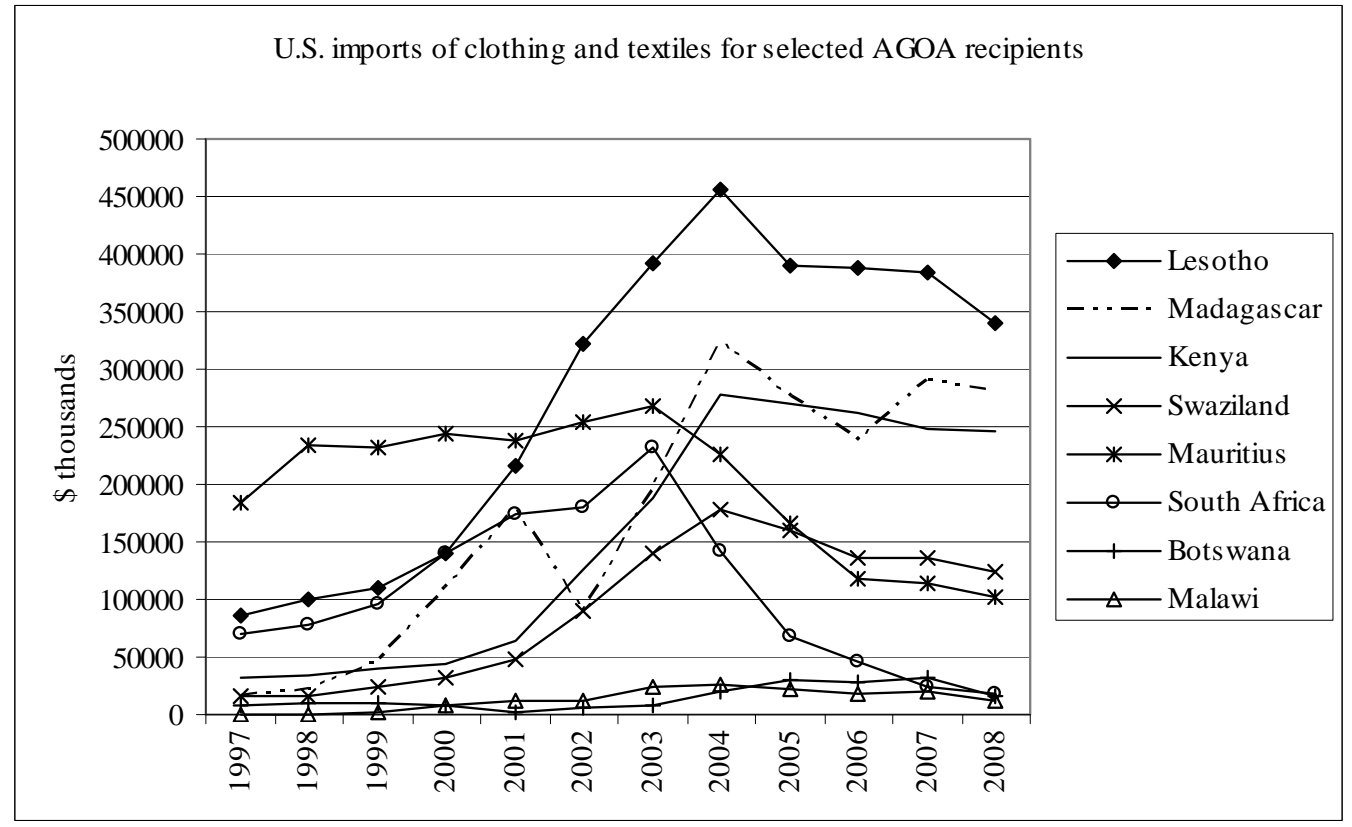

Source: USITC 
Figure 3: Apparel exports to the EU 15, selected AGOA countries

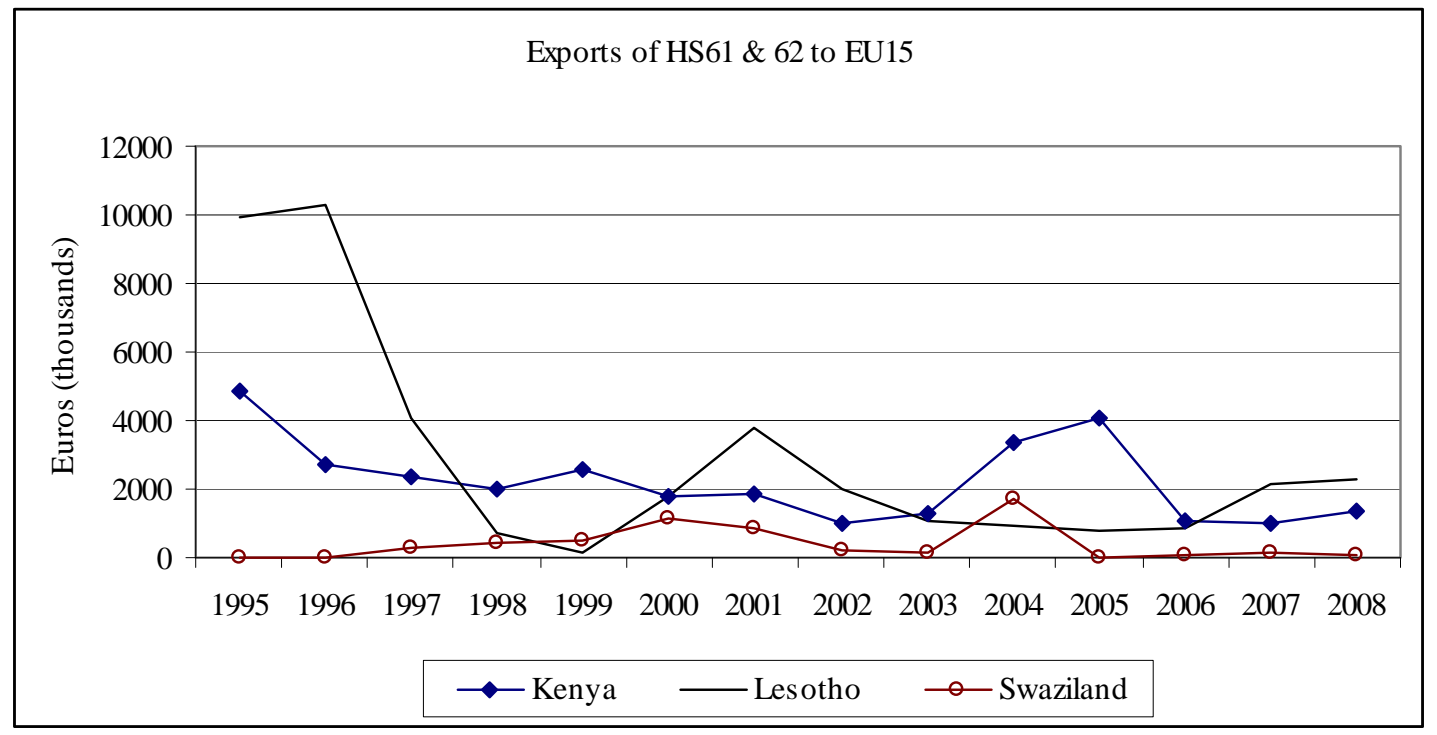

Notes: Own calculations using data from Eurostat (http://epp.eurostat.ec.europa.eu/newxtweb )

Figure 4: Lesotho apparel exports to US according to Chinese quota fill rates

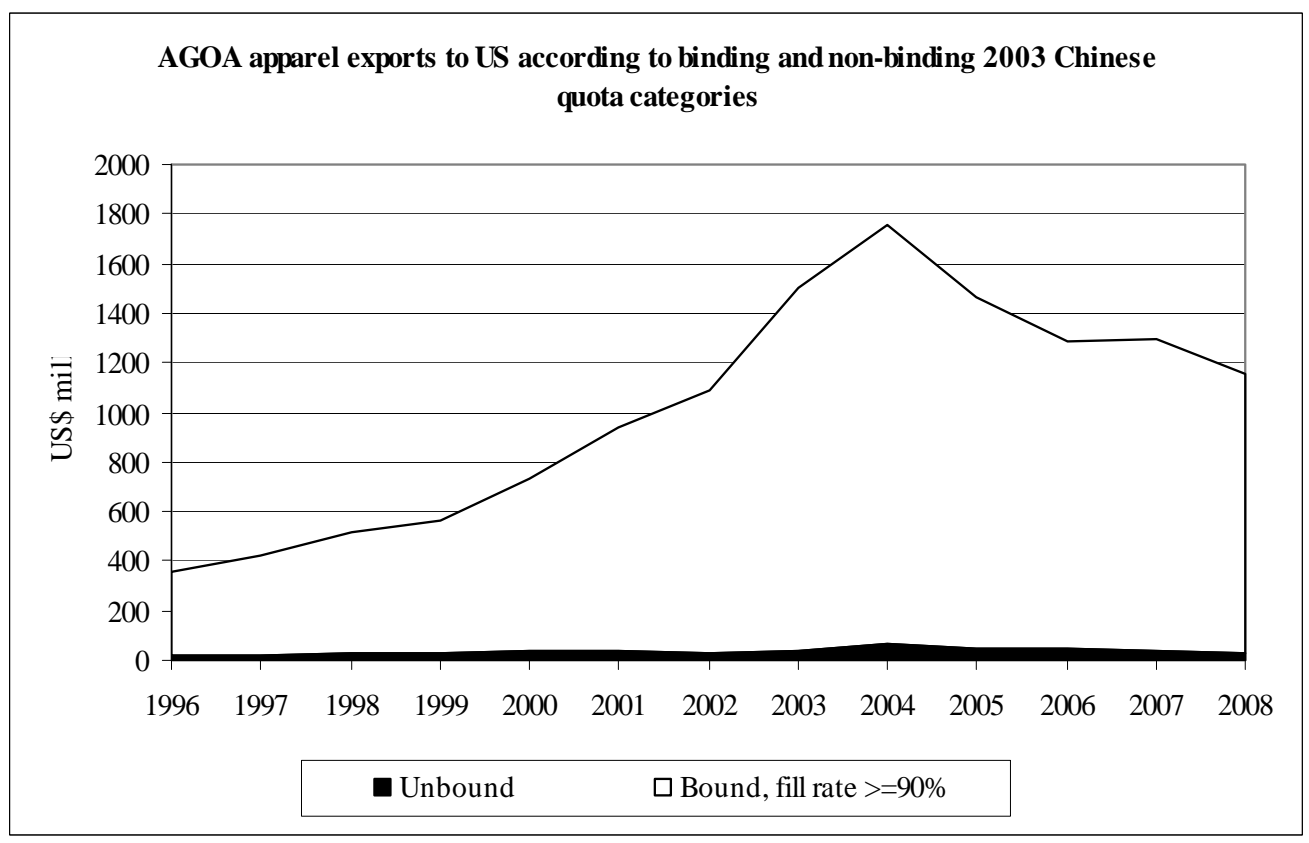

Notes: Quota fill rates are obtained from OTEXA ((http://otexa.ita.doc.gov/). Quotas on product lines are assumed binding if the 2003 Chinese fill rate is greater than or equal to $90 \%$. 
Figure 5: The effect of tariff preferences on incentive to export fabric-intensive products

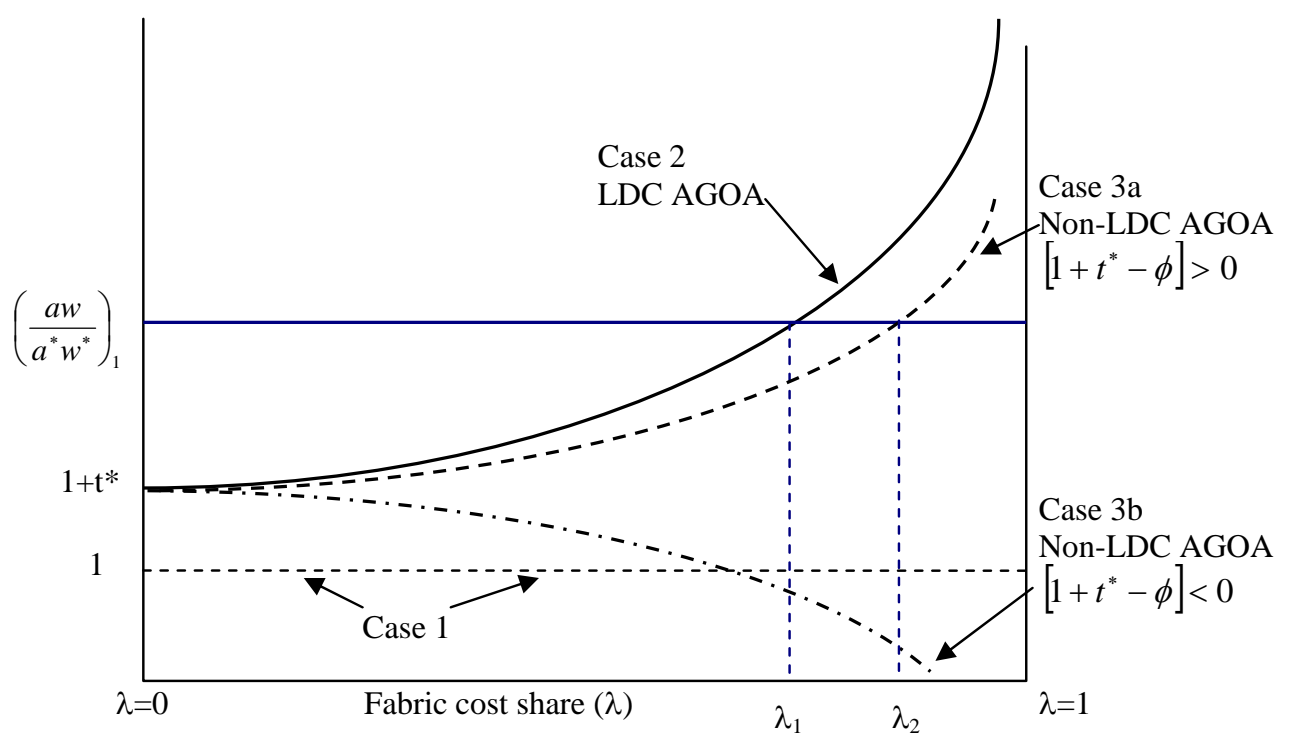

Figure 6: Unit values and level of development: Top Apparel product exported by Lesotho in 2004 (Women's or girls' other pullovers of cotton, knitted).

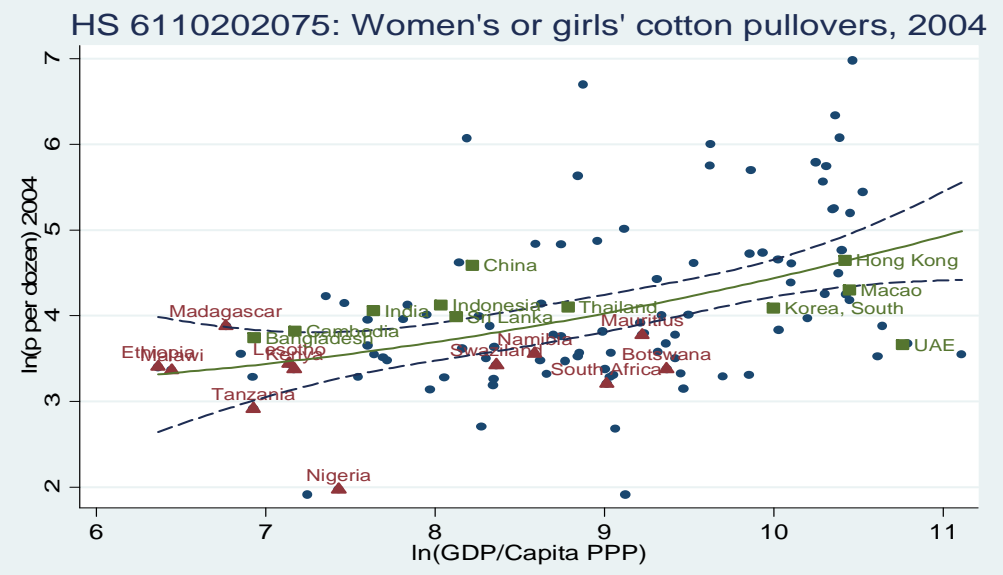

Notes: Triangles are AGOA countries eligible to export apparel. Square blocks reflect the top quota restricted countries from 1984-2004 as identified by Brambilla et al. (2010) 
Figure 7: Fabric price indices

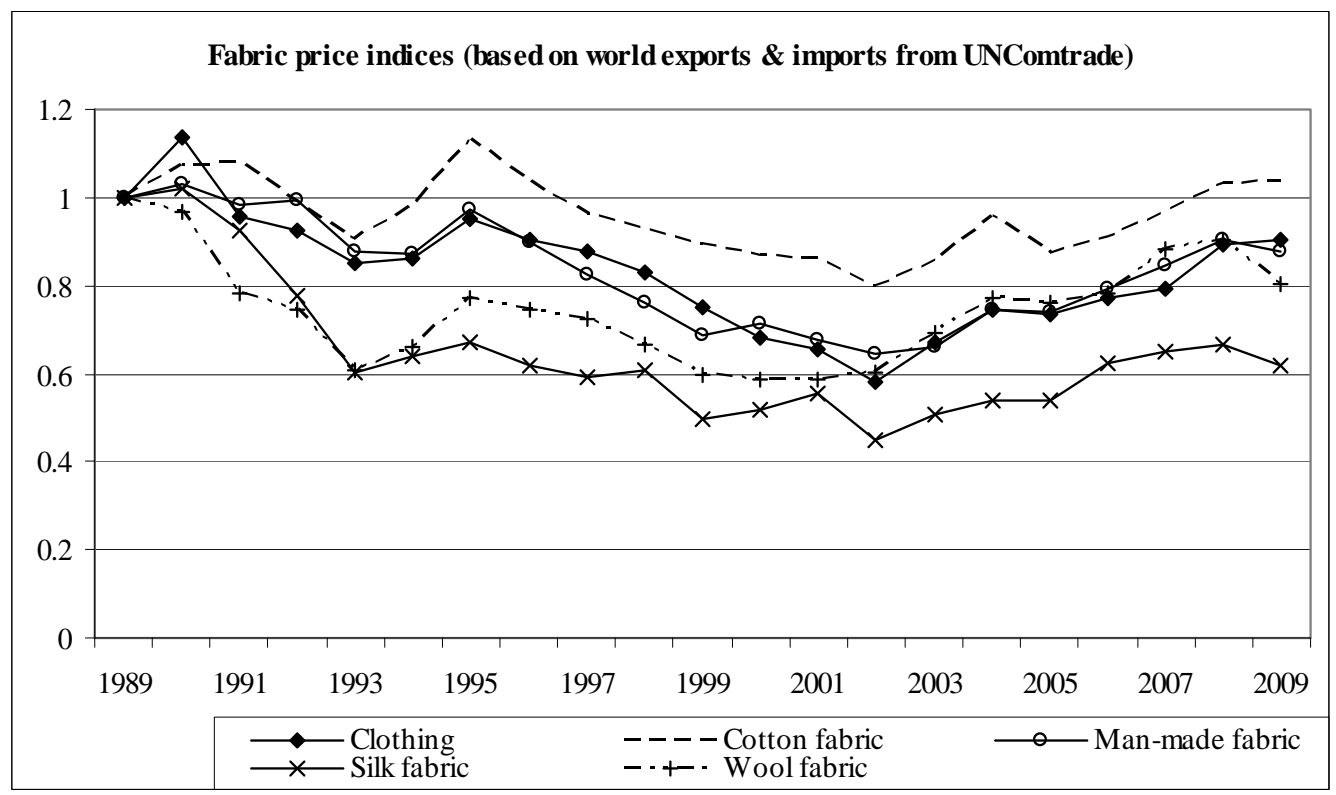

Notes: Based on Tornqvist price index constructed using hs 6-digit unit values obtained from UnComtrade trade data. Hs 6-digit product lines for fabric (HS (50 - silk, 51-wool, fine animal hair, 52 cotton, 54-man made fiber, 55 - man-made staple).

\section{Figure 8: Import weighted average price relative to Lesotho}

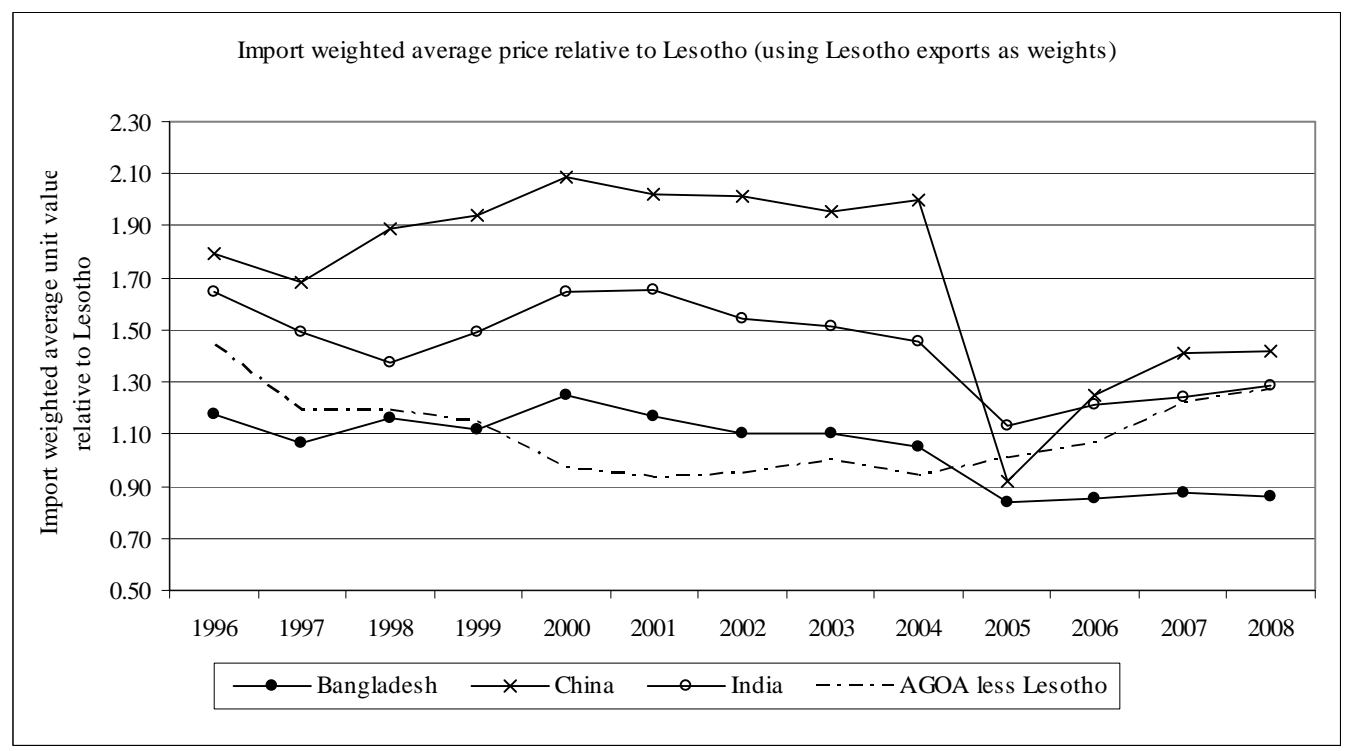

Note: The import weighted average price for country $c$ is calculated as $\bar{p}_{c t}=\prod\left(p_{i c t} / p_{i L t}\right)^{w_{i t}}$ where $w_{i L t}$ is the share of product $i$ in Lesotho's apparel exports to the US, $P_{i L T}$ is the price of Lesotho exports and $P_{i c t}$ is the price of the comparator country apparel exports. 
Figure 9: Structural shifts in the composition of US apparel imports

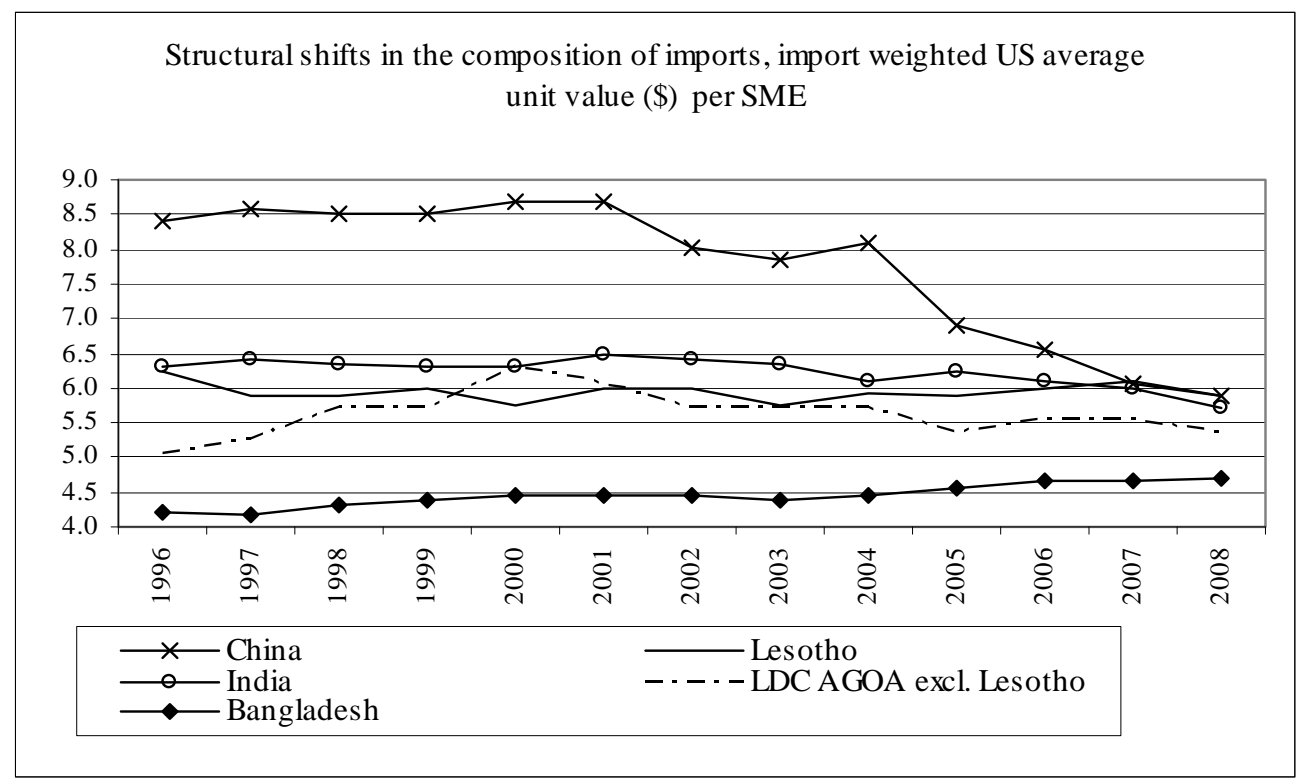

Note: The import weighted average price for country $c$ is calculated as $p s m e_{c t}=\sum m_{i c t} \bar{p}_{i}$ where $\bar{p}_{i}$ is the median price of product $i$ over the entire period and $m_{i c t}$ is the share of $i$ in country $c$ 's apparel exports to the US. 
Table A1: Price equation estimates by 4-digit HS level

\begin{tabular}{|c|c|c|c|c|c|c|c|c|c|c|c|c|c|}
\hline \multirow[b]{2}{*}{ Description } & \multirow{2}{*}{$\begin{array}{r}\text { Coefficients } \\
\ln (\mathrm{GDP} \\
\text { worker) }\end{array}$} & \multirow[b]{2}{*}{$\ln (\mathbf{p f})$} & \multirow[b]{2}{*}{$\ln (\mathbf{p v a})$} & \multirow{2}{*}{\multicolumn{2}{|c|}{$\begin{array}{rr} & \ln (\text { Pcomp } \\
\text { (e) } & \text { ete) }\end{array}$}} & \multirow[b]{2}{*}{$\ln ($ US ppi) } & \multirow[b]{2}{*}{$\ln (1+t)$} & \multirow[b]{2}{*}{$\mathbf{N}$} & \multirow[b]{2}{*}{$\mathbf{F}$} & \multirow[b]{2}{*}{ r2 } & \multicolumn{3}{|c|}{$\begin{array}{r}\text { Hypothesis tests (p- } \\
\text { value) }\end{array}$} \\
\hline & & & & & & & & & & & $\begin{array}{r}\text { HOD } \\
1\end{array}$ & $\delta_{1}+\delta_{2}=\beta_{2}$ & $\begin{array}{r}\text { Erate }= \\
\text { tariff }\end{array}$ \\
\hline 6101 men's or boys' overcoats etc, knit or crochet & -0.186 & $0.329 * *$ & $0.217 * * *$ & $-0.660 * * *$ & 0.062 & -0.439 & $0.873^{* *}$ & 2890 & 7.19 & 0.024 & 0.169 & 0.072 & 0.003 \\
\hline 6102 women's or girls' overcoats etc, knit or crochet & $-0.530 * * *$ & 0.199 & $0.420 * * *$ & $-0.704 * * *$ & $0.107 * *$ & -0.546 & 0.047 & 3833 & 14.3 & 0.035 & 0.719 & 0.048 & 0.397 \\
\hline 6103 men's or boys' suits, ensembles etc, knit or croch & $-0.282 * * *$ & $0.358 * * *$ & $0.326 * * *$ & $-0.672 * * *$ & $0.062 * *$ & $0.774 * * *$ & $-1.265 * * *$ & 8136 & 17.6 & 0.024 & 0.122 & 0.714 & 0.002 \\
\hline 6104 women's or girls' suits, ensemb etc, knit or croch & $-0.319 * * *$ & $0.406 * * *$ & $0.358^{* * *}$ & $-0.812 * * *$ & $0.070 * * *$ & $1.444^{* * *}$ & -0.244 & 24243 & 76.2 & 0.030 & 0.001 & 0.011 & 0.772 \\
\hline 6105 men's or boys' shirts, knitted or crocheted & 0.071 & $0.469 * * *$ & $0.331^{* * *}$ & $-0.678^{* * *}$ & $0.150^{* *}$ & $0.649 *$ & -0.293 & 4272 & 14.8 & 0.035 & 0.118 & 0.001 & 0.928 \\
\hline 6106 women's or girls' blouses \& shirts, knit or croch & -0.149 & $0.231^{* *}$ & $0.255^{* * *}$ & $-0.555^{* * *}$ & $0.161^{* * *}$ & 0.539 & $-0.557 *$ & 5332 & 15.1 & 0.027 & 0.651 & 0.114 & 0.731 \\
\hline 6107 men's or boys' underpants, pjs, etc, knit or croch & -0.384 & $0.752^{* *}$ & -0.13 & $-1.377 * * *$ & $0.262 * *$ & 0.274 & 1.029 & 2321 & 3.96 & 0.018 & 0.902 & 0.008 & 0.658 \\
\hline 6108 women's or girls' slips, pjs, etc, knit or crochet & $-0.454 * * *$ & $0.439 * * *$ & $0.370^{* * *}$ & $-0.912^{* * *}$ & $0.064 *$ & 0.238 & $-1.884 * * *$ & 10262 & 33.7 & 0.033 & 0.794 & 0.003 & 0.000 \\
\hline 6109 t-shirts, singlets, tank tops etc, knit or crochet & $-0.105^{*}$ & $0.225^{* * *}$ & $0.273^{* * *}$ & $-0.632 * * *$ & 0.023 & $0.780^{* * *}$ & 0.042 & 14877 & 39.1 & 0.025 & 0.067 & 0.000 & 0.027 \\
\hline 6110 sweaters, pullovers, vests etc, knit or crocheted & $-0.179 * * *$ & $0.574 * * *$ & $0.298 * * *$ & $-0.819 * * *$ & $0.056 * * *$ & $0.406^{* *}$ & $-0.423 * * *$ & 29316 & 98.4 & 0.031 & 0.041 & 0.003 & 0.100 \\
\hline 6111 babies' garments \& accessories, knit or crocheted & -0.299 & 0.241 & $0.381^{* * *}$ & $-0.829 * * *$ & $0.229 * * *$ & $1.329 * *$ & 1.139 & 5254 & 20.8 & 0.048 & 0.054 & 0.101 & 0.082 \\
\hline 6112 track suits, ski-suits \& swimwear, knit or crochet & $-0.442 * * *$ & $0.736^{* * *}$ & $0.286^{* * *}$ & $-1.101 * * *$ & $0.079 * *$ & $1.894^{* * *}$ & -0.367 & 6478 & 24.4 & 0.033 & 0.004 & 0.067 & 0.239 \\
\hline 6113 garments, knit etc, coated etc rubber, plastic etc & 0.037 & $1.015^{* * *}$ & -0.034 & $-1.180^{* * *}$ & 0.076 & 0.989 & $4.128 *$ & 2653 & 8.76 & 0.030 & 0.162 & 0.036 & 0.099 \\
\hline 6114 garments nesoi, knitted or crocheted & $-0.375^{* * *}$ & $0.647^{* * *}$ & $0.279 * * *$ & $-1.028 * * *$ & 0.016 & -0.181 & -0.43 & 9940 & 33.5 & 0.031 & 0.484 & 0.004 & 0.114 \\
\hline 6115 pantyhose, socks \& other hosiery, knit or crochet & $-0.348^{* *}$ & $0.151 *$ & $0.609 * * *$ & $-0.718 * * *$ & 0.047 & $1.775^{* *}$ & -0.564 & 5535 & 18 & 0.030 & 0.036 & 0.379 & 0.728 \\
\hline 6116 gloves, mittens and mitts, knitted or crocheted & $-0.677 * * *$ & $0.689 * * *$ & $0.441^{* * *}$ & $-1.108^{* * *}$ & -0.054 & 0.725 & $-1.525 * * *$ & 5314 & 21.5 & 0.032 & 0.132 & 0.779 & 0.005 \\
\hline 6117 made-up clothing access nesoi. parts etc. knit etc & $-0.561 * * *$ & $0.367^{* *}$ & $0.392 * * *$ & $-0.678^{* * *}$ & $0.096^{* * *}$ & $3.312^{* * *}$ & -0.866 & 5824 & 15.7 & 0.023 & 0.000 & 0.304 & 0.435 \\
\hline 6201 men's or boys' overcoats, cloaks etc, not knit etc & 0.032 & $0.343^{* * *}$ & $0.351^{* * *}$ & $-0.638 * * *$ & $0.068^{* *}$ & -0.403 & -0.225 & 12265 & 34.8 & 0.026 & 0.089 & 0.050 & 0.556 \\
\hline 6202 women's or girls' overcoats etc, not knit or croch & -0.043 & $0.410^{* * *}$ & $0.354 * * *$ & $-0.788 * * *$ & 0.013 & -0.509 & $-0.438 * *$ & 14450 & 57 & 0.035 & 0.294 & 0.183 & 0.296 \\
\hline 6203 men's or boys' suits, ensembles etc, not knit etc & 0.057 & $0.238 * * *$ & $0.358 * * *$ & $-0.573^{* * *}$ & $0.100^{* * *}$ & $0.698^{* * *}$ & $-0.579 * * *$ & 22945 & 72.3 & 0.030 & 0.026 & 0.199 & 0.398 \\
\hline 6204 women's or girls' suits, ensemb etc, not knit etc & -0.009 & $0.447 * * *$ & $0.368 * * *$ & $-0.822 * * *$ & $0.044 * * *$ & $0.797 * * *$ & $-0.504 * * *$ & 50694 & 245 & 0.044 & 0.019 & 0.510 & 0.043 \\
\hline 6205 men's or boys' shirts, not knitted or crocheted & 0.113 & $0.368 * * *$ & $0.319 * * *$ & $-0.641 * * *$ & -0.035 & $0.924^{* * *}$ & $-0.718 * * *$ & 6467 & 19.2 & 0.029 & 0.087 & 0.168 & 0.198 \\
\hline 6206 women's or girls' blouses, shirts etc not knit etc & 0.028 & $0.453^{* * *}$ & $0.205^{* * *}$ & $-0.704 * * *$ & $0.052 *$ & $0.989^{* * *}$ & $-0.687 * * *$ & 7965 & 38.3 & 0.042 & 0.037 & 0.085 & 0.119 \\
\hline 6207 men's or boys' undershirts etc, not knit or croch & -0.068 & 0.352 & 0.263 & $-0.987 * * *$ & -0.071 & 0.628 & -2.315 & 2337 & 4.27 & 0.024 & 0.893 & 0.105 & 0.249 \\
\hline 6208 women's or girls' slips etc, not knit or crochet & -0.095 & $0.306^{* * *}$ & $0.195^{* * *}$ & $-0.577 * * *$ & $0.116^{* * *}$ & -0.463 & $-1.424 * * *$ & 7748 & 15.5 & 0.021 & 0.064 & 0.077 & 0.001 \\
\hline 6209 babies' garments \& accessories, not knit or croch & $-0.358^{* *}$ & $0.602 * * *$ & $0.238^{* *}$ & $-1.258 * * *$ & -0.084 & 0.923 & -0.923 & 3786 & 19.9 & 0.054 & 0.329 & 0.002 & 0.118 \\
\hline 6210 garments, of felt etc, or fabric impregnated etc & $-0.299 * * *$ & $0.429 * * *$ & $0.149 * *$ & $-0.577 * * *$ & -0.052 & -0.093 & -0.137 & 7067 & 5.03 & 0.007 & 0.315 & 0.978 & 0.561 \\
\hline 6211 track suits, ski-suits \& swimwear, not knit etc & -0.046 & $0.386^{* * *}$ & $0.289 * * *$ & $-0.674^{* * *}$ & $0.079 * * *$ & $0.582^{* * *}$ & $0.555^{* *}$ & 28191 & 54.1 & 0.018 & 0.144 & 0.937 & 0.001 \\
\hline 6212 bras, girdles, garters etc., knitted etc or not & -0.117 & $0.509 * * *$ & $0.390 * * *$ & $-0.854 * * *$ & -0.049 & $1.165^{*}$ & $-1.159 * *$ & 5872 & 21.8 & 0.032 & 0.101 & 0.382 & 0.072 \\
\hline 6213 handkerchiefs & $-0.758^{* *}$ & 0.147 & 0.053 & $-1.064 * * *$ & -0.044 & $11.178^{* * *}$ & 1.781 & 1049 & 4.38 & 0.046 & 0.001 & 0.001 & 0.428 \\
\hline 6214 shawls, scarves, mufflers, mantillas, veils etc. & -0.097 & -0.04 & $0.208^{*}$ & -0.099 & $0.156^{*}$ & 2.429 & -0.055 & 3625 & 2.66 & 0.007 & 0.246 & 0.448 & 0.162 \\
\hline 6215 ties, bow ties \& cravats, not knitted or crocheted & $-0.817 * * *$ & -0.157 & $0.733 * * *$ & $-0.472 * * *$ & $0.126 * *$ & 0.823 & 0.318 & 1974 & 6.86 & 0.031 & 0.519 & 0.247 & 0.284 \\
\hline
\end{tabular}


6216 gloves, mittens and mitts, not knit or crocheted

6217 made-up clothing access nesoi, garment etc parts nesoi

6406 parts of footwear: insoles etc: gaitors etc, parts

6501 hat forms/bodies, hoods, plateaux \& manchons of felt

6502 hat shapes, plaited or assembled strips any material

6503 felt hats \& other felt headgear from heading 6501

6504 hats \& other headgear,plaitd/assmbld strips any material

6505 hats \& headgear, knit etc, lace, etc in pc, hr net

$\begin{array}{rrrrrrr}-0.027 & 0.897 * * * & 0.232^{*} & -0.945^{* * *} & -0.033 & -1.059 & -0.737 \\ -0.571^{* *} & 0.102 & 0.323^{* *} & -0.627^{* * *} & -0.006 & 8.474^{* * *} & -0.019 \\ -1.000^{* *} & -0.699 & 0.713^{* *} & -0.06 & -0.012 & 4.351^{* *} & 1.158 \\ 0.359 & 1.500^{*} & -0.629 & -0.838 & -0.054 & 1.703 & -2.434 \\ -0.243 & 0.656 & -0.117 & -0.75 & 0.136^{*} & 3.266^{*} & -0.79 \\ 0.498 & 2.189 & -0.012 & -2.288^{* *} & -0.046 & 1.255 & -81.49 * * * \\ -0.099 & 0.126 & 0.214 & -0.595^{* *} & 0.228^{* *} & 0.754 & -0.658^{*} \\ -0.300^{* * *} & 0.545^{* * *} & 0.278^{* * *} & -0.817^{* * *} & 0.151^{* * *} & 0.554^{* *} & -1.285^{* *}\end{array}$

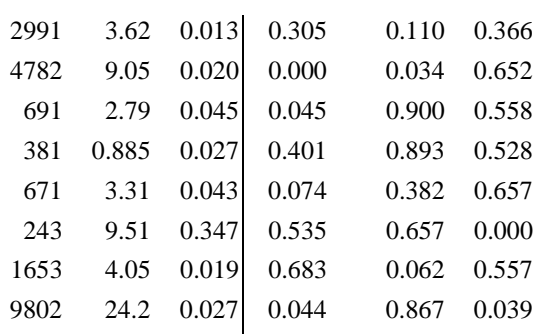

Overall, the coefficients are broadly consistent with expectations. In most sectors the coefficient on fabric prices is positive and ranges from 0.23 to just over 1. Similarly, the coefficients on value added prices and the exchange rate are mostly of the correct sign. The estimates for Headgear (HS 64) and Footwear (HS 65) products are poor, but is likely that the fabric costs indices do not adequately reflect the inputs used in the production of these products. For example, HS 6406 covers Parts of Footwear; Removable In-Soles, Heel Cushions And Similar Articles; Gaiters, Leggings etc. HS65 covers headgear products often comprising of felt, strips of any material, lace, etc. These products also make up a very small proportion of AGAO country exports. Most estimates fail to reject the homogeneity and symmetric pass-through (both the tariffs and exchange rate \& exchange rate and production costs) hypotheses. Each hypothesis is rejected at most 12 times (out of 40). 